NUREG/CR-

ORNL/TM-2000/360

\title{
A REVIEW OF LARGE-SCALE FRACTURE EXPERIMENTS RELEVANT TO PRESSURE VESSEL INTEGRITY UNDER PRESSURIZED THERMAL SHOCK CONDITIONS
}

Manuscript Completed: November 2000

Date Published:

Prepared by

C. E. Pugh and B. R. Bass

Oak Ridge National Laboratory

Managed and Operated by UT-Battelle, LLC

P.O. Box 2009

Oak Ridge, TN 37831-8063 USA

C. G. Santos, NRC Project Manager

Prepared for

Division of Engineering Technology

Office of Nuclear Regulatory Research

U.S. Nuclear Regulatory Commission

Washington, DC 20555-0001

NRC Job Code W6631 


\title{
A REVIEW OF LARGE-SCALE FRACTURE EXPERIMENTS RELEVANT TO PRESSUREVESSEL INTEGRITY UNDER PRESSURIZED THERMAL SHOCK CONDITIONS
}

\author{
C. E. Pugh and B. R. Bass
}

\begin{abstract}
Numerous large-scale fracture experiments have been performed over the past thirty years to advance fracture mechanics methodologies applicable to thick-wall pressure vessels. This report first identifies major factors important to nuclear reactor pressure vessel (RPV) integrity under pressurized thermal shock (PTS) conditions. It then covers 20 key experiments that have contributed to identifying fracture behavior of RPVs and to validating applicable assessment methodologies. The experiments are categorized according to four types of specimens: (1) cylindrical specimens, (2) pressurized vessels, (3) large plate specimens, and (4) thick beam specimens. These experiments were performed in laboratories in six different countries. This report serves as a summary of those experiments, and provides a guide to references for detailed information.
\end{abstract}

Key words

pressure vessels, pressurized thermal shock, ferritic steel, fracture, brittle, ductile, crack-arrest. 


\section{CONTENTS}

Page

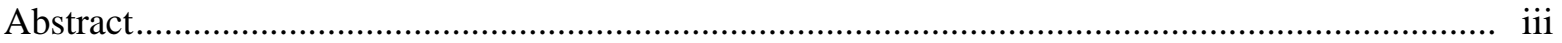

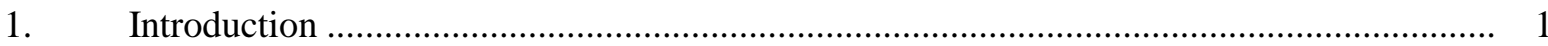

2. $\quad$ Factors Important to RPV Integrity Under PTS Conditions........................................... 2

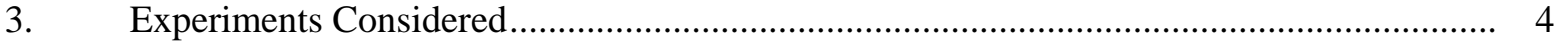

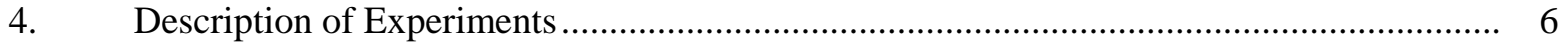

$4.1 \quad$ Tests with Cylindrical Specimens ..................................................................... 6

4.2 Tests with Vessel Specimens ................................................................................ 11

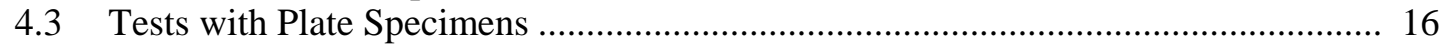

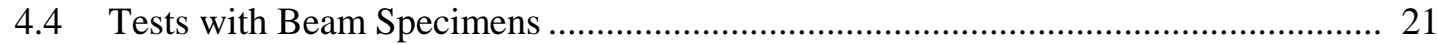

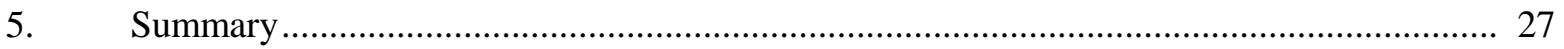

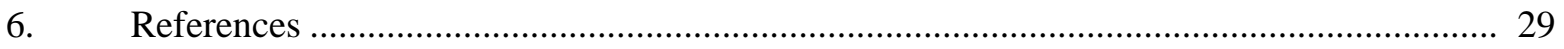

\section{Figures}

1. Facility for thermal-shock tests with spinning cylinders (AEA Technology,

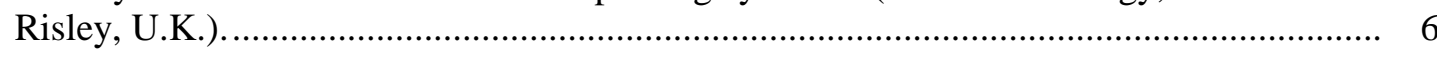

2. Test cylinder and crack geometry for SC-4 experiment (AEA_Risley, U.K.)................... 7

3. Cylindrical specimen used in NKS-3 through -6 experiments (measures in $\mathrm{mm}$ ) (MPA-Stuttgart, Germany) .................................................................................. 9

4. Thermal-shock test cylinder and facility (ORNL, USA) .......................................... 11

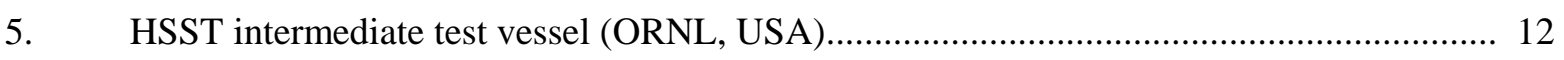

6. Vessel ITV-6 experienced ductile failure under pressure loads (ORNL, USA)................ 13

7. Pressurized-thermal-shock (PTS) vessel inside shroud (ORNL, USA), .......................... 14

8. Specimen and crack geometry used in PTS-I/6 experiment (Pometey

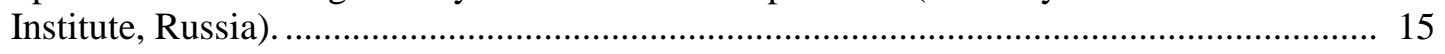

9. Test facility used to conduct the PTS-I/6 experiment (Prometey Institute, Russia)........... 16

10. Specimen and crack geometry for the step B plate test (JAPEIC, Japan)....................... 17

11. HSST wide-plate, crack-arrest specimen (ORNL, USA) ........................................... 18

12. HSST wide-plate specimen prior to being attached to long pull tabs (ORNL, USA). 
13. High-temperature crack-arrest toughness data from large-specimen tests

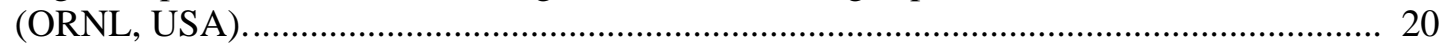

14. Overall crack-arrest specimen GP-1 (dimensions in mm) (MPA, Germany).................... 21

15. Test frame used in four-point bending fracture experiments (EdF, France) ..................... 22

16. Clad bend-bar specimens, DD2 and DSR3, containing shallow semielliptical underclad cracks (EdF, France) ................................................................................. 22

17. Prototypical flaw depths and metallurgical gradients were used in full-thickness beam tests (ORNL, USA) ....................................................................................... 23

18. Cruciform beam specimen used in biaxial-loading effects tests ORNL, USA)................. 24

19. Clad cruciform specimens cut from an RPV shell segment and used to investigate initiation behavior of prototypical RPV welds (ORNL, USA)

\section{Tables}

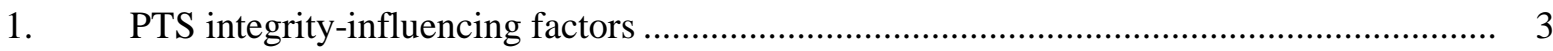

2. PTS experiments and performing organization ..................................................... 5 


\section{INTRODUCTION}

Because pressurized thermal shock (PTS) represents the most comprehensive problem in RPV integrity assessment, experimental validation of analytical methods and limiting criteria embody essentially every aspect of material and component behavior. Over the past several years, studies at research organizations in many countries have included comprehensive separate-effects investigations as well as carefully-designed large-scale component tests that include simultaneous mechanical and thermal-shock loadings. Historically, large-scale experiments have been defined to (1) reveal material and structural integrity behavior under prototypical conditions, (2) validate analysis methods, and/or (3) demonstrate applicability of code criteria (and limits) used in safety analyses. When these motivations are combined with the various RPV designs, different materials, and aging considerations, the variety of separate-effects studies becomes large.

This report summarizes 20 experiments that were selected because of their relevance to factors that influence RPV integrity under PTS conditions. The authors recognize that numerous other relevant tests have been performed, but space and time do not permit complete comprehensive coverage. Rather, the selected experiments reflect the range of tests conducted over the past three decades and collectively illustrate the progress that has been made and the role that large-scale tests have played in advancing RPV integrity technology. In this report, some experiments are covered in more detail than others, in part because of the authors' familiarity and, in part, because of the amount of information available in the open literature. Readers should consult the references listed at the end of this report to gain a detailed knowledge of individual experiments.

The second section in this report identifies eight fracture-influencing factors considered in relation to PTS experiments. Section 3 identifies the 20 experiments that were selected for characterization. These tests were performed by research organizations in six different countries, and they are grouped in this report according to the type of specimen used. Section 4 describes each test and gives a brief summary of the results. The final section of this report provides some observations about the contribution that large-scale experiments have made to the overall RPV integrity technology and how they have served as a catalyst to bring about international collaboration and networks. 


\section{FACTORS IMPORTANT TO RPV INTEGRITY UNDER PTS CONDITIONS}

As described in other sections of this document, PTS scenarios give rise to complex thermal and pressure loading conditions, and several factors contribute to the impact that these loadings can have on RPV integrity. For example, the loadings are multiaxial, transient in time, and most severe at (and near) the inner surface of the RPV where property degradation is the greatest due to radiation exposure and where base metal, weld metal, and cladding interface. Consequently, shallow surface (or near-surface) flaws in weldments are most susceptible to propagation. In addition to being most severely loaded, these flaws are highly influenced by constraint conditions and the fact that yield and fracture behavior of RPV steels are history dependent. Thus, the specific steel, its condition, nature of existing flaws, and the time/temperature of maximum loading all impact the margin from RPV fracture. Recognition of these facts has led investigators to conduct experiments to better understand features of RPV behavior, such as the effects of constraint (including effects of free-surfaces), multiaxial loading, warm prestressing, and cladding on the propensity for flaw propagation. Correspondingly, if crack propagation is initiated, will the running crack arrest, will it be stable after arrest (or will propagation be reinitiated), how can mode conversion occur, and what are the implications to vessel rupture?

Whereas the experiments addressed several separate-effects, eight major factors have been highlighted most often: (1) flaw characterization, (2) constraint effects, (3) material property sensitivity, (4) fracture mode conversion, (5) residual stresses, (6) warm prestressing, (7) role of crack arrest, and (8) cladding effects. Each of these factors is characterized further in Table 1. 
TABLE 1. PTS INTEGRITY-INFLUENCING FACTORS

\begin{tabular}{|c|c|}
\hline Integrity-Influencing Factors & Characterizing Aspects \\
\hline 1. Flaw Characterization & $\begin{array}{ll}- & \text { effects of size, shape, and orientation of flaws } \\
- & \text { effects of flaw location, (surface, shallow, or embedded) } \\
- & \text { effects of under-clad versus through-clad flaws }\end{array}$ \\
\hline 2. Constraint Conditions & $\begin{array}{ll}\text { - } & \text { effects of shallow flaws on effective toughness } \\
\text { - } & \text { effects of multiaxial loading on fracture toughness } \\
\text { effectiveness of single- and dual-parameter fracture } \\
\text { prediction methods }\end{array}$ \\
\hline 3. Material Properties Sensitivity & $\begin{array}{ll}\text { - } & \text { low upper-shelf toughness } \\
\text { - } & \text { weld versus base metal } \\
\text { - } & \text { high transition temperature }\end{array}$ \\
\hline $\begin{array}{l}\text { 4. Ductile/Cleavage Mode } \\
\text { Conversion }\end{array}$ & $\begin{array}{ll}\text { - } & \text { conversion from cleavage propagation to ductile tearing } \\
\text { - } & \text { effects of pre-cleavage ductile tearing } \\
\text { - } & \text { predictions of mode conversion to cleavage }\end{array}$ \\
\hline 5. Residual Stresses & $\begin{array}{ll}\text { - } & \text { effects of structural welds } \\
\text { - } & \text { effects of clad/base metal coefficient of thermal expansion }\end{array}$ \\
\hline 6. Warm Prestressing & $\begin{array}{l}\text { - } \quad \text { types of warm prestressing observed in experiments } \\
\text { - } \quad \text { effects on delaying onset of cleavage initiation }\end{array}$ \\
\hline 7. Role of Crack Arrest & $\begin{array}{ll}\text { - } & \text { arrest in rising } \mathrm{K} \text { fields } \\
\text { - } & \text { reinitiation of arrested cracks } \\
\text { - } & \text { relationship to mode conversion }\end{array}$ \\
\hline 8. Cladding Effects & $\begin{array}{ll}\text { - } & \text { effects of variations in tensile properties } \\
\text { - } & \text { effects of variations in fracture-toughness properties } \\
\text { (includes both cleavage and ductile tearing) } \\
\text { - } \quad \text { effects on shallow flaw initiation }\end{array}$ \\
\hline
\end{tabular}




\section{EXPERIMENTS CONSIDERED}

Table 2 lists 20 experiments selected for inclusion in this review along with several key references for each. References [1-4] are particularly noteworthy because they provide summaries of several experiments. (References [5,6] are open-literature summaries of [1,2].) These tests were conducted by various research organizations, and each was designed to reveal information relative to at least one of the influencing factors cited in Table 1. For convenience, these experiments are grouped under the type of specimen employed. Specifically, there are four specimen groups: (1) cylindrical specimens, (2) pressurized vessel specimens, (3) plate specimens, and (4) beam specimens. The actual specimens were fabricated of prototypical RPV steels, including plate, forging, and weld materials. Some of the specimens included prototypical cladding, and others included steels that had been heat-treated or possess a special chemistry to simulate near-end-of-life (degraded properties) conditions.

Another feature of this group of tests is that some were conducted in the 1960s and 1970s, while others were conducted more recently. For example, the Intermediate Test Vessel (ITV) series of experiments were among the early tests conducted under the Heavy-Section Steel Technology (HSST) program for the U.S. Nuclear Regulatory Commission (NRC). Those and other early tests were aimed at establishing the fundamental fracture behavior of thick vessels under pressure loadings at temperatures ranging from the brittle fracture to the ductile fracture regimes. On the other hand, the first test under the European Network for Evaluation of Steel Components (NESC-1) was conducted in early 1997 and addresses many synergistic aspects of RPV behavior under PTS conditions. The IAEA International Working Group on Life Management of Nuclear Power Plants (LMNPP) and the Nuclear Energy Agency's (NEA) Committee on Safety of Nuclear Installations (CSNI) have, through international projects and specialists' meetings, served as a focus to share information from a significant number of large-scale experiments [1-6]. 
TABLE 2. PTS EXPERIMENTS AND PERFORMING ORGANIZATION

\begin{tabular}{|c|c|c|c|c|}
\hline $\begin{array}{c}\text { Exper. } \\
\text { Number }\end{array}$ & Experiment Title & Research Organization & Country & $\begin{array}{l}\text { Reference } \\
\text { Numbers }\end{array}$ \\
\hline \multicolumn{5}{|c|}{ TESTS WITH CYLINDRICAL SPECIMENS } \\
\hline NKS-3 & $\begin{array}{l}\text { Thermal Shock } \\
\text { Experiment } 3\end{array}$ & Materialprufungsanstalt (MPA) & Germany & $1,4,7,8$ \\
\hline NKS-4 & $\begin{array}{l}\text { Thermal Shock } \\
\text { Experiment } 4\end{array}$ & Materialprufungsanstalt (MPA) & Germany & $\begin{array}{l}1,3,4 \\
8,9\end{array}$ \\
\hline NKS-5 & $\begin{array}{l}\text { Thermal Shock } \\
\text { Experiment } 5\end{array}$ & Materialprufungsanstalt (MPA) & Germany & 2,10 \\
\hline NKS-6 & $\begin{array}{l}\text { Thermal Shock } \\
\text { Experiment } 6\end{array}$ & Materialprufungsanstalt (MPA) & Germany & 2,10 \\
\hline $\mathrm{SC}-1$ & $\begin{array}{l}\text { Spinning Cylinder PTS } \\
\text { Experiment } 1\end{array}$ & AEA Technology & UK & $1,4,11-13$ \\
\hline $\mathrm{SC}-2$ & $\begin{array}{l}\text { Spinning Cylinder PTS } \\
\text { Experiment } 2\end{array}$ & AEA Technology & UK & $1,4,13$ \\
\hline $\mathrm{SC}-4$ & $\begin{array}{l}\text { Spinning Cylinder PTS } \\
\text { Experiment } 4\end{array}$ & AEA Technology & UK & $2,14,15$ \\
\hline NESC-1 & $\begin{array}{l}\text { Spinning Cylinder PTS } \\
\text { Experiment }\end{array}$ & $\begin{array}{l}\text { JRC-Petten, Joint Research Center } \\
\text { AEA Technology }\end{array}$ & $\begin{array}{l}\text { NL } \\
\text { UK }\end{array}$ & 16,17 \\
\hline TSE-7 & $\begin{array}{l}\text { Thermal Shock Cylinder } \\
\text { (Cylinder with Short Flaws) }\end{array}$ & Oak Ridge National Laboratory (ORNL) & USA & $4,18-21$ \\
\hline TSE-8 & $\begin{array}{l}\text { Thermal Shock Cylinder } \\
\text { (Clad Cylinder) }\end{array}$ & Oak Ridge National Laboratory (ORNL) & USA & $4,20-22$ \\
\hline \multicolumn{5}{|c|}{ TESTS WITH PRESSURIZED VESSELS } \\
\hline ITV 1-8 & Intermediate Test Vessels & Oak Ridge National Laboratory (ORNL) & USA & $23-27$ \\
\hline PTSE-1 & $\begin{array}{l}\text { Pressurized Thermal- } \\
\text { Shock Experiment }\end{array}$ & Oak Ridge National Laboratory (ORNL) & USA & $\begin{array}{c}1,3 \\
28,29\end{array}$ \\
\hline PTSE-2 & $\begin{array}{l}\text { Pressurized Thermal- } \\
\text { Shock Experiment }\end{array}$ & Oak Ridge National Laboratory (ORNL) & USA & $\begin{array}{l}1,3,4 \\
29,30\end{array}$ \\
\hline PTS I/6 & $\begin{array}{l}\text { Pressurized Thermal } \\
\text { Shock Experiment I/6 }\end{array}$ & $\begin{array}{l}\text { Central Research Institute for Structural } \\
\text { Materials (CRISM), Prometey, }\end{array}$ & Russia & 2,31 \\
\hline \multicolumn{5}{|c|}{ TESTS WITH PLATE SPECIMENS } \\
\hline $\begin{array}{l}\text { PTS } \\
\text { STEP B }\end{array}$ & $\begin{array}{l}\text { Wide-Plate PTS Step B } \\
\text { Experiment }\end{array}$ & $\begin{array}{l}\text { Japan Power and Engineering Inspection } \\
\text { Corporation (JAPEIC) }\end{array}$ & Japan & $\begin{array}{c}1,4 \\
32-34 \\
\end{array}$ \\
\hline WP-1 \& -2 & $\begin{array}{l}\text { Wide Plate Crack Arrest } \\
\text { Tests of A533B and LUS } \\
\text { Steels }\end{array}$ & Oak Ridge National Laboratory (ORNL) & USA & $\begin{array}{c}3, \\
35-38\end{array}$ \\
\hline GP-1 & Wide Plate Test & Materialprufungsanstalt (MPA) & Germany & 4,39 \\
\hline \multicolumn{5}{|c|}{ TESTS WITH BEAM SPECIMENS } \\
\hline $\begin{array}{l}\text { DD-2 \& } \\
\text { DSR-3 }\end{array}$ & Clad Beam Experiments & Electricite de France (EdF) & France & 2,40 \\
\hline $\begin{array}{l}\text { SENB } \\
\text { RPV Steel }\end{array}$ & $\begin{array}{l}\text { Full Thickness Clad Beam } \\
\text { Experiments }\end{array}$ & $\begin{array}{l}\text { National Institute of Standards and Testing } \\
\text { (NIST) \& Oak Ridge National Laboratory } \\
\text { (ORNL) }\end{array}$ & USA & 41 \\
\hline $\mathrm{CB}$ & $\begin{array}{l}\text { Cruciform Beam (CB) } \\
\text { Experiments }\end{array}$ & Oak Ridge National Laboratory (ORNL) & USA & 2,42 \\
\hline
\end{tabular}




\section{DESCRIPTION OF EXPERIMENTS}

The 20 selected experiments are discussed below according to the four principal types of specimens used: cylinders, vessels, plates, and beams. The experiments are described in terms of the actual specimens used, the test facility employed, and a general indication of major results. Due to space limitations, this report cannot be comprehensive, but through the study of the references cited, one can explore each of these tests in detail.

\subsection{Tests with cylindrical specimens}

Nine of the tests cited in Table 2 used thick-wall circular-cylindrical specimens. These were: (1) the Spinning Cylinder Tests conducted at AEA Technology in the U.K., (2) the NKS Experiments conducted at Staatliche Materialprufungsanstalt (MPA), Stuttgart, and (3) the Thermal Shock Experiments (TSEs) performed at the Oak Ridge National Laboratory (ORNL). These three groups of experiments utilized specimens of similar size, materials that are representative of RPV applications, and thermal-shock loadings. However, they employed a wide range of mechanical loadings and axial constraints. A summary description of each group is given below.

\subsubsection{Spinning cylinder tests}

AEA Technology (Risley, U.K.) developed the test facility shown in Fig. 1, which is described in detail in [11]. Mechanical loads are applied to large cylindrical specimens by spinning them at high rotational speeds, and thermal loads are then applied by cooling the inside surface by a water spray. A flexible shaft from a pivoted bearing suspends the 8-ton specimen (1.3-m long, 1.4-m OD, 200-mm wall thickness) so that it is free to rotate about the vertical axis. A dc motor provides the driving force, and the maximum rotational speed is $3500 \mathrm{rpm}$. Eight heaters are mounted inside the

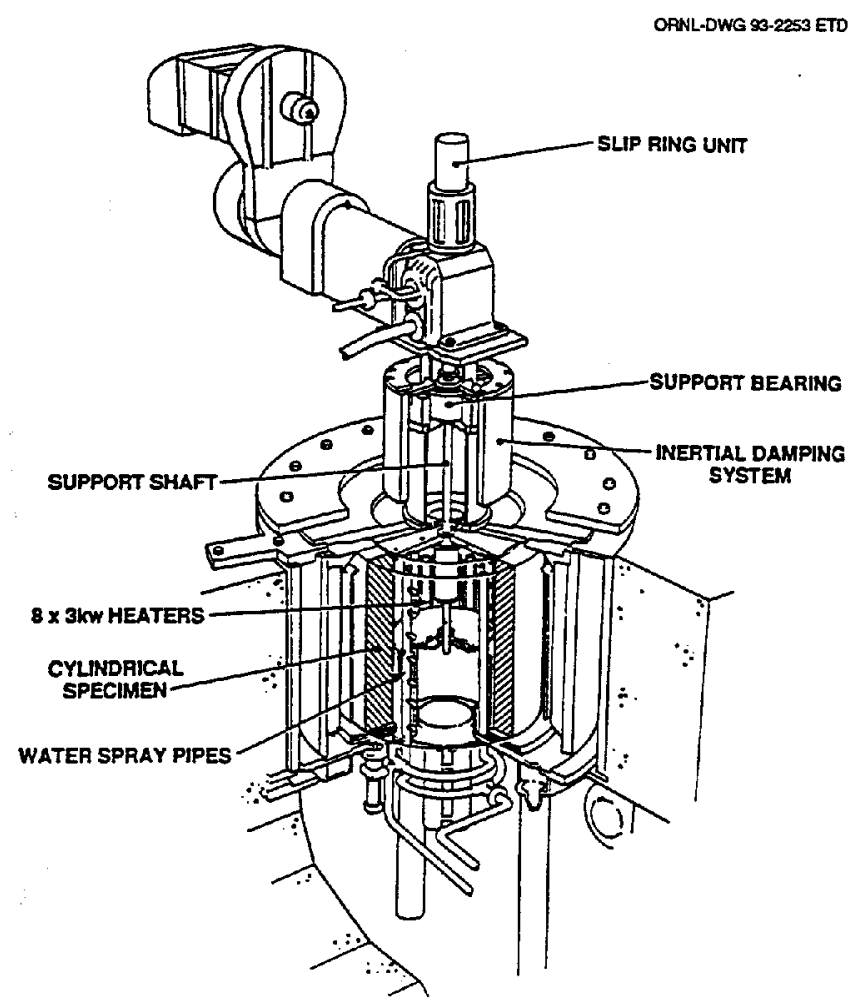

Fig. 1.

Facility for thermal-shock tests with spinning cylinders (AEA Technology, Risley, U.K.). 
specimen to heat it to $290^{\circ} \mathrm{C}$, and a stationary water spray system is mounted within the cylinder to apply the thermal shocks. Axial flaws were inserted on the inner surface of each test cylinder. Material properties were obtained by testing specimens taken from a prolongation to the test cylinders.

The first test (SC-1) was an investigation of stable ductile crack growth under contained yield conditions when the cylinder was subjected to mechanical loads only (rotated at progressively increasing speed). The second test (SC-2) was an investigation of stable crack extension under contained yield conditions when the cylinder was subjected to a severe thermal shock. Both specimens SC-1 and SC-2 contained long axial flaws. The fourth test (SC-4) investigated fracture behavior under simultaneous severe thermal shock and mechanical loadings. As shown in Fig. 2, SC4 specimen contained two relatively short axial flaws which were semicircular in the through thickness direction (radii of 40 and $60 \mathrm{~mm}$ ). Results from the first two experiments were analyzed by a large number of international organizations as part of the CSNI project Fracture Analyses of LargeScale International Reference Experiments (FALSIRE) [1]. References [43, 44] also provide analyses of SC-1. Stable ductile crack growth occurred in SC-1 and SC-2, but predictions from classical tearing models did not agree well in all aspects. SC-4 was included in the second FALSIRE project and is described in $[2,14]$. There was axial growth from both ends of the short flaws. There was no radial growth at the deepest point of either flaw, but the 60-mm flaw exhibited a thin ligament between the crack extension and the inner surface of the cylinder. This tendency for short flaws to become long is consistent with results from other tests, such as ORNL's TSE-7 and PTSE-1 experiments (discussed later in this report).
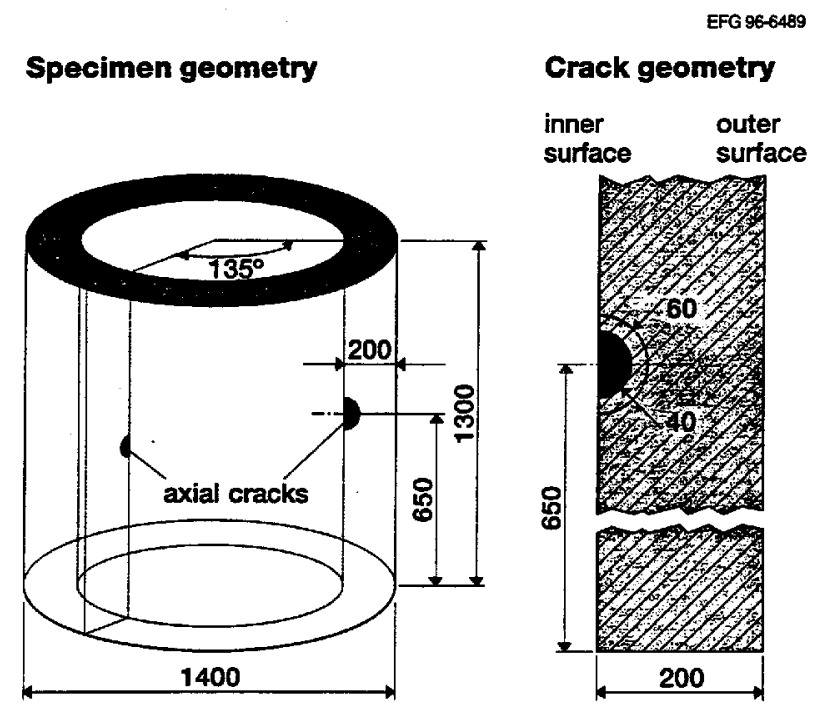

All measures in mm

Fig. 2. Test cylinder and crack geometry for SC-4 experiment (AEA-Risley, U.K.).

\subsubsection{NESC-1 Experiment}

The NESC-1 experiment, sponsored jointly by the U.K. Health and Safety Executive (HSE) and the European Commission (EC), represents the initial research project organized within the European Network for Evaluating Structural Components (NESC). The objective of NESC is to foster the exchange of information among participating international organizations on the safety assessment 
of structural components used in the nuclear industry [17]. The countries participating in NESC include several in Europe (Austria, Belgium, United Kingdom, France, Germany, Netherlands, Spain, Italy, Sweden, Finland, and Switzerland), as well as Japan and the United States. The NESC-1 experiment was a spinning cylinder experiment, conducted at the AEA Technology facility at Risley, U.K. The project embodies the total process of structural integrity assessment of aged RPVs containing surface-breaking and subclad cracks by means of inspection of the specimen and extensive pretest and posttest analyses.

The project consists of several phases. The specimen was fabricated from A508B Class-3 steel [inner diameter of $1.045 \mathrm{~m}$; wall thickness of $175 \mathrm{~mm}$ (includes $4 \mathrm{~mm}$ of cladding); length of 1.3 $\mathrm{m}$; and weight of 8 tons]. It was heat treated to produce fracture-toughness properties and residual stresses representative of those in the beltline region of a RPV after 30 years' service. Several cracks of varying sizes were inserted in the inner surface prior to application of stainless-steel cladding. In the pretest phases of the project, the size and location of the subclad cracks were not revealed to participants. Characterization blocks were fabricated for determination of properties of the cladding, heat-affected zone (HAZ), and base metal. The cylinder was inspected by teams using in-service inspection NDE methods which were applied under conditions that were as realistic as possible.

Sixteen international organizations performed pretest safety assessments of the cracks based on interpretation of the inspection results, specified PTS loading, and materials property data. The cylinder was fully instrumented and tested (on March 20, 1997) under simulated PTS loading. The test conditions were determined from recommendations made by the participating analysts. Data from strain gages monitored during the test provided a strong indication of crack extension. Following the test, the cylinder was made available for posttest inspection. The cylinder was destructively examined to determine the dimensions of the initial cracks and the extent of crack propagation during the test. Comparisons were made between the pre- and posttest inspections and safety assessments and the observed size and evolution of the cracks.

\subsubsection{NKS Experiments}

MPA-Stuttgart conducted a series of NKS experiments on thick cylindrical specimens under combined tensile, internal pressure and thermal-shock loadings. These tests were to investigate crack growth and crack-arrest behavior of RPV materials. The test facility was capable of applying $100-\mathrm{MN}$ tensile load and internal pressure of $30 \mathrm{MPa}$. In addition to the tensile and pressure loads, thermal-shock loading was achieved by spraying cold water evenly over the inner surface of the specimen. The specimens for NKS-3 through -6 are illustrated in Fig. 3, and the tests are described in [1-10]. (Two similar NKS experiments are employed in the NESC-2 program.) 

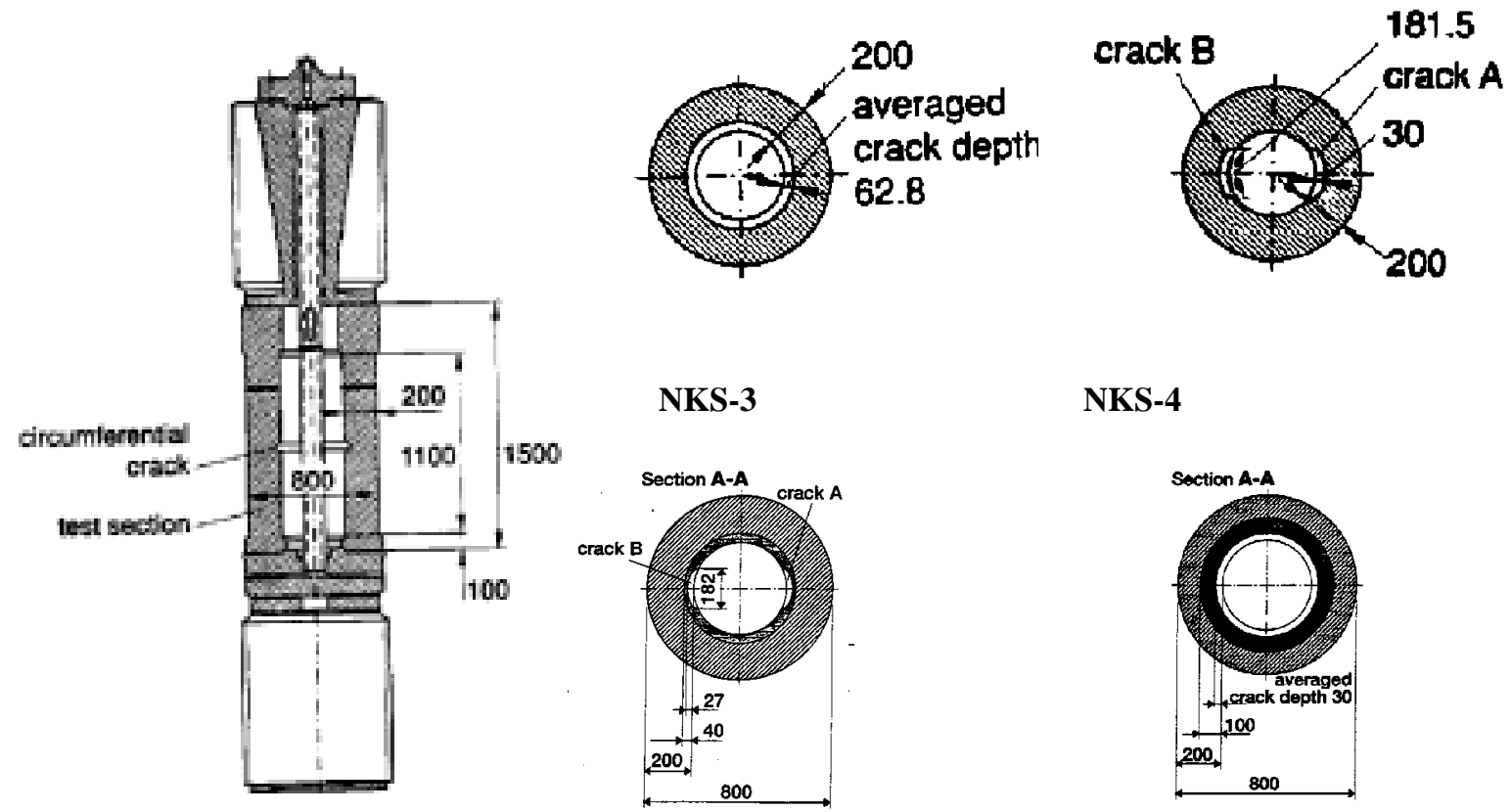

NKS-3

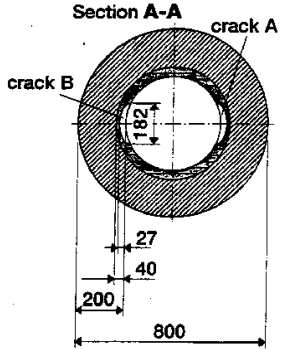

NKS-5
NKS-4

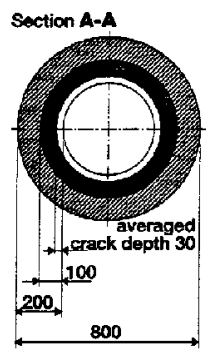

NKS-6

Fig. 3. Cylindrical specimen used in NKS-3 through -6 experiments (measures in $\mathrm{mm}$ ) (MPA-Stuttgart, Germany).

Specimen NKS-3 contained a 360-degree circumferential flaw on the inner surface with an average depth of $62.8 \mathrm{~mm}$, and the material was 22Ni Mo Cr $37 \mathrm{RPV}$ steel (upper-shelf toughness 95J). At the beginning of the thermal shock, the specimen was at $332^{\circ} \mathrm{C}$. On average, the crack grew in a ductile manner $3.6 \mathrm{~mm}$.

Specimen NKS-4 examined growth of two symmetrically located semielliptical surface flaws in a low-toughness material (upper-shelf toughness 60J). Under the combined loadings, the two flaws in NKS-4 grew in a ductile stable manner in the radial direction, but at noticeably different rates. The difference was attributed to inhomogeneous material properties.

Specimen NKS-5 was made of an inner ring of base material (22Ni Mo Cr 37, USE $90 \mathrm{~J}$ ) surrounded by a shape-welded external ring (S3 Ni Mo 1, USE 220J). The specimen contained two cracks on opposite sides of the inner ring of base material. During the tests, the cracks initiated in the ductile regime and extended in radial and circumferential direction. Initiation in the large-scale specimen occurred at the same level of toughness as in small-scale specimens. The crack extensions were essentially by cleavage without subsequent ductile tearing. Due to constraint effects, the crack propagation was by cleavage, though the main events took place in the beginning of the upper shelf of fracture toughness [10].

NKS-6 was conducted to investigate unstable crack propagation and arrest in a very low toughness vessel material [17 Mo V 84 (K 22), USE $30 \mathrm{~J}$ ] under combined loadings. The specimen contained a 360 -degree circumferential crack (37-mm depth) in a $100-\mathrm{mm}$ thick inner ring of the K 22 steel, which is surrounded by an outer ring of weld material like that, used in NKS-5. After the tensile, pressure, and thermal-shock loads were applied, the crack propagated in two steps with the final arrest occurring at the interface to the outer ring. The first extension was by cleavage, which was 
followed by a period of arrest prior to the second extension being by ductile tearing. Further discussion of both NKS-5 and -6 is given in [10].

Overall the NKS series of tests has investigated a range of issues through the use of various materials, finite and continuous shallow flaws, and a wide range of multiaxial loadings. The results have provided, for example, illustrations of the effects of constraint on initiation of shallow flaws under PTS conditions and temperatures in the transition regime. They have also provided information useful to assessing fracture methodologies that include multiaxial stress effects, interactions between fracture modes, and sensitivity to material properties (e.g., USE levels).

\subsubsection{Thermal Shock Experiments}

During the 1970s and 1980s, ORNL performed ten thermal shock experiments (TSEs) as part of the Heavy-Section Steel Technology (HSST) Program which was sponsored by the U.S. Nuclear Regulatory Commission (NRC). The TSEs used open-end thick-walled cylinders that were shocked from a uniform temperature (e.g., $288^{\circ} \mathrm{C}$ ) by an influx of liquid nitrogen. (Figure 4 shows the general geometry of the specimens and the test apparatus.) A variety of flaw configurations were used in these tests, and the RPV steels used had been heat treated to provide various toughness conditions. Seven of these tests are discussed in [18-22]. TSE-7 and TSE-8 are chosen for inclusion in this report because they contained short flaws and clad specimens, respectively.

TSE-7 was conducted using a high-toughness RPV steel with short semicircular flaw (37-mm long and 14-mm deep) on the inner surface. This experiment is described in [19]. A great deal of effort was devoted to obtaining good heat transfer from the liquid nitrogen to the specimen in order to gain the desired temperature gradient through the wall of the specimen. The purpose was to demonstrate that in the absence of cladding an initially short surface flaw would extend on the surface in a single event to become a long flaw. During the test, the shallow flaw experienced three major initiation/arrest events and, during the first event, extended on the surface, and bifurcated many times, to become a very long flaw. The pretest analysis, which could not include the potential for bifurcation, indicated that the flaw would extend on the surface nearly the full length of the test cylinder in a single event and subsequently experience two more initiation/arrest events with a fourth event being prevented by warm prestressing. Thus, there was generally good agreement between prediction and experiment.

TSE-8 was conducted to evaluate the behavior of subclad flaws. During this test, one of six flaws experienced two initiation/arrest events, extending both the length and depth of the flaw. Although there were obvious stretch marks in the cladding over the extended flaw, there was no penetration of the cladding. This experiment demonstrated that even in the presence of tough cladding, a short flaw could extend in length beneath the cladding to effectively become a 2-D subclad flaw. Comparing TSE-8 with TSE-7 indicates that the presence of the cladding reduces the tendency for bifurcation and thus the extent of the "surface" extension. Reference [20-22] describes this experiment in detail. 


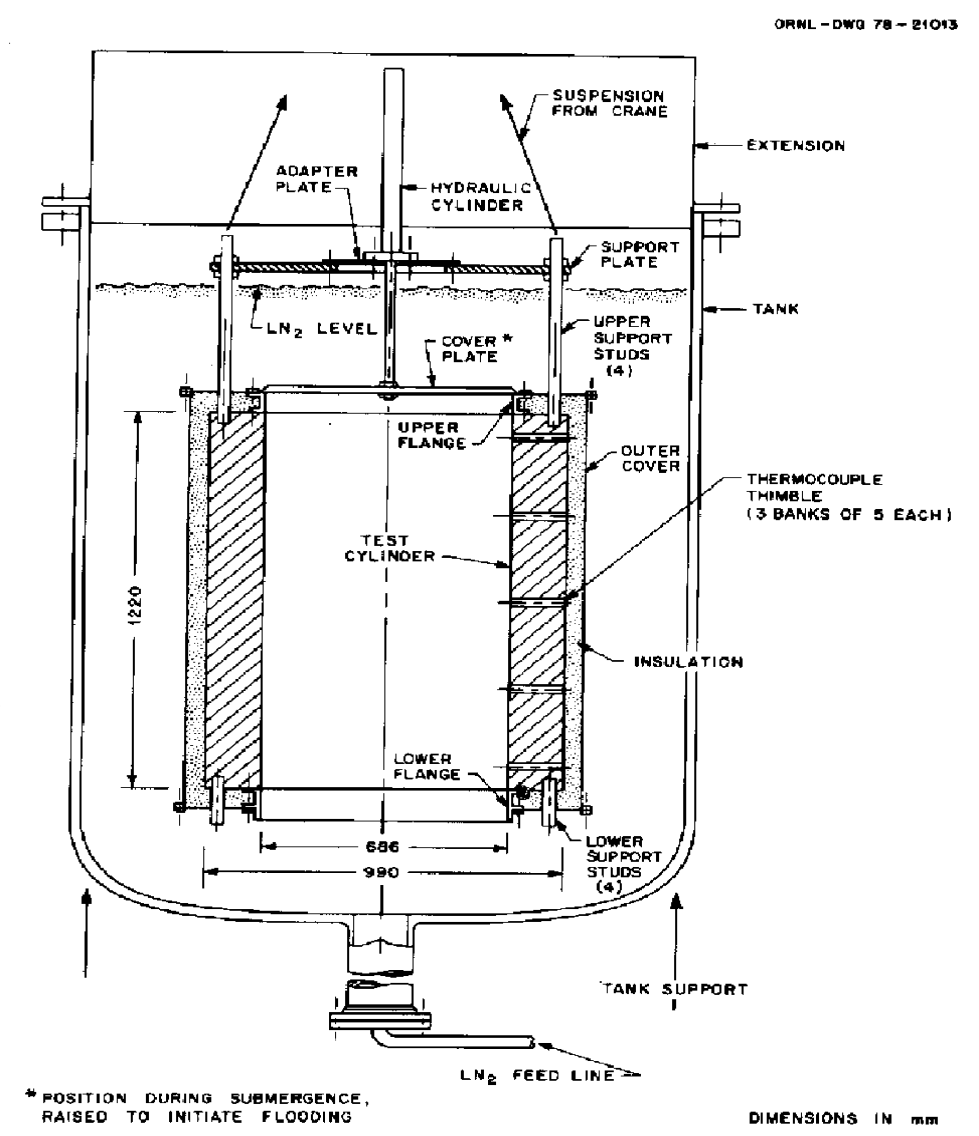

Fig. 4. Thermal-shock test cylinder and facility (ORNL USA).

\subsection{Tests with vessel specimens}

\subsubsection{Pressure vessel integrity under pressure loading}

The experimental study of RPV integrity has over the past 30 years progressed systematically from "separate effects" studies to examinations under combined transient conditions. For example, there was a long early phase of experimental examinations of the fracture behavior of thick vessels under pressure loadings at various temperatures. These experiments made significant contributions to nuclear safety codes and standards, such as underpinning of the fracture-toughness curves and pressure-temperature limits in the ASME-Boiler and Pressure Vessel Code.

The HSST Program at ORNL carried out a significant part of these studies through a series of experiments using Intermediate Test Vessels (ITVs). Over a ten-year period, 12 ITV experiments were conducted using to: (1) demonstrate transition temperature behavior in vessels (demarcation between brittle and ductile fracture behavior) and (2) verify methods of analysis that could be used to predict fracture behavior over a range of conditions in heavy-section thickness. References [23-27, $45,46]$ provide detailed descriptions of the ITV experiments, the results obtained, and comparisons between predictions and experimental data. As illustrated in Fig. 5 and shown in Fig. 6, these tests involved 150-mm-thick vessel specimens that were made of prototypical forging steels and weld metal. The various tests produced cleavage fracture, stable tearing with the intercession of cleavage fracture, stable tearing, and leak without break in plates, forgings, and weldments. 
The vessel shown in Fig. 6 was used in experiment ITV-6 that was a test under internal pressure and at a temperature that corresponded to the Charpy upper-shelf region. The vessel was fabricated of A508, Class 1 steel. The flaw exhibited ductile behavior after the vessel was exposed to a pressure well in excess of the design allowable value, and the wall was fully plastic prior to ductile tearing of the flaw.

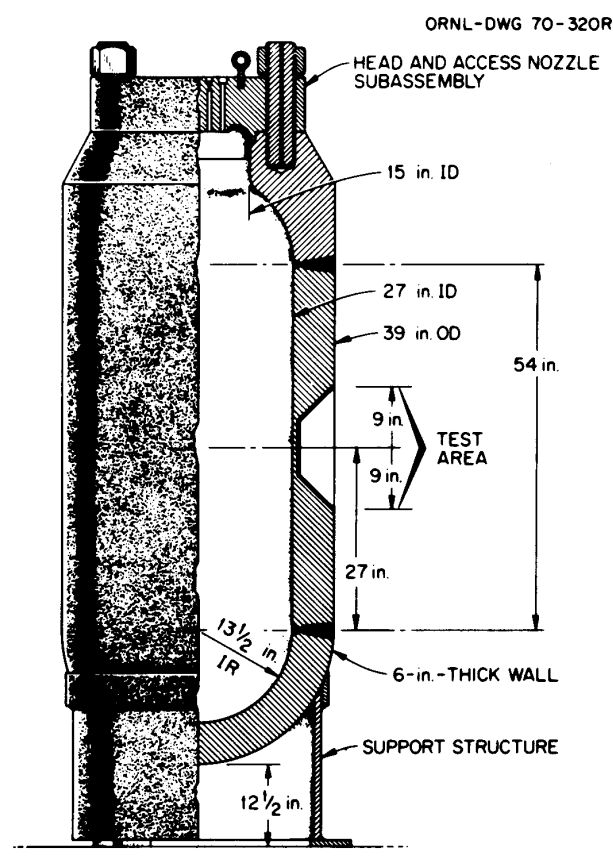

Fig. 5. HSST intermediate test vessel (ORNL, USA). 


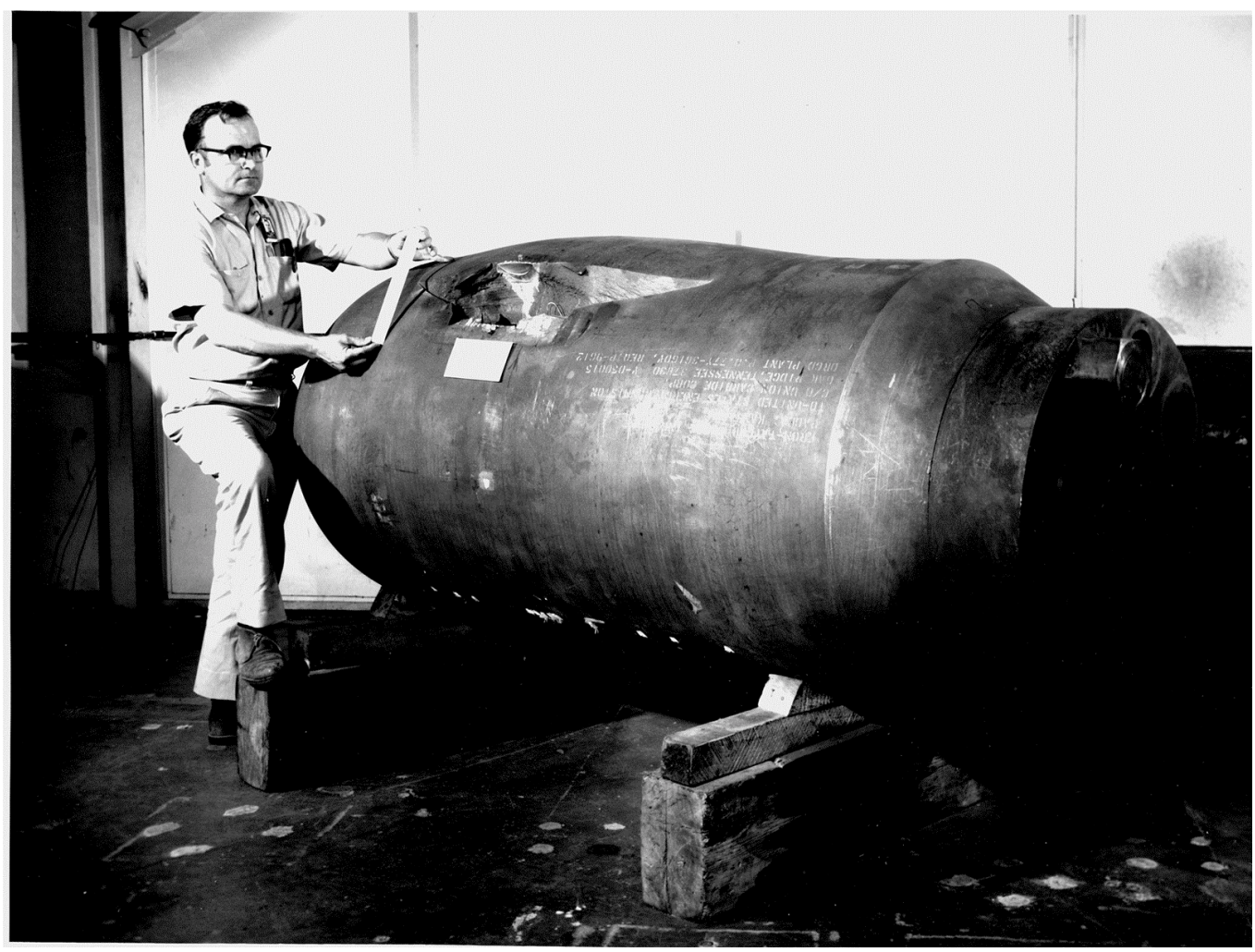

Fig. 6. Vessel ITV-6 experienced ductile failure under pressure loads (ORNL, USA).

In addition to individual reports on the ITV experiments, Ref. [46] summarizes the significance of this series of tests through ITV-7. The principal observations and conclusions from [46] are:

1. Fracture analysis methods were validated using thick-section structures and appropriate stress states.

2. Fracture pressure levels were significantly greater than pressures allowed under the ASME code.

3. Methods for calculating fracture toughness from small specimens were successfully used in applications of fracture analysis of flawed vessels in relevant materials.

4. In-service weld repair procedures, including the residual stress and effects of materials characterization, were evaluated.

5. Nondestructive inspection techniques were evaluated in vessels where flaw geometry was accurately characterized by posttest inspections.

6. The vessels were observed to generally sustain loads three times design pressure when large flaws were present, thus confirming the existence of the intended margin of safety for full-scale vessels.

\subsubsection{Pressurized thermal-shock experiments}

The HSST Program at ORNL also conducted two very carefully controlled PTS experiments using ITV specimens similar to that depicted in Fig. 5 and described in the previous paragraph. These experiments were designed to challenge the predictions of analytical methods applicable to full-scale RPVs under combined pressure and thermal transient loadings. Materials and test conditions provided stress fields, gradients, and fracture-toughness conditions around shallow flaws that were characteristic of RPVs subjected to postulated PTS transients. Each vessel contained a long, sharp and shallow flaw (on its external surface), as is assumed in U.S. regulatory evaluations. The flawed 
vessels were enclosed in an outer vessel as shown schematically in Fig. 7. The outer vessel was electrically heated to bring the vessel to a uniform initial temperature of $290^{\circ} \mathrm{C}$. A thermal transient was initiated by suddenly injecting chilled water or a methanol-water mixture into the annulus between the two vessels. Pressurization of the test vessel was controlled independently by a system capable of pressures up to about $100 \mathrm{MPa}$. The specimen was carefully instrumented to measure the temperature transients, through-the-wall temperature distributions, pressure transients, and crackmouth opening displacements. References [28-30] give detail descriptions of the tests, test results, and comparison between analyses and test data.

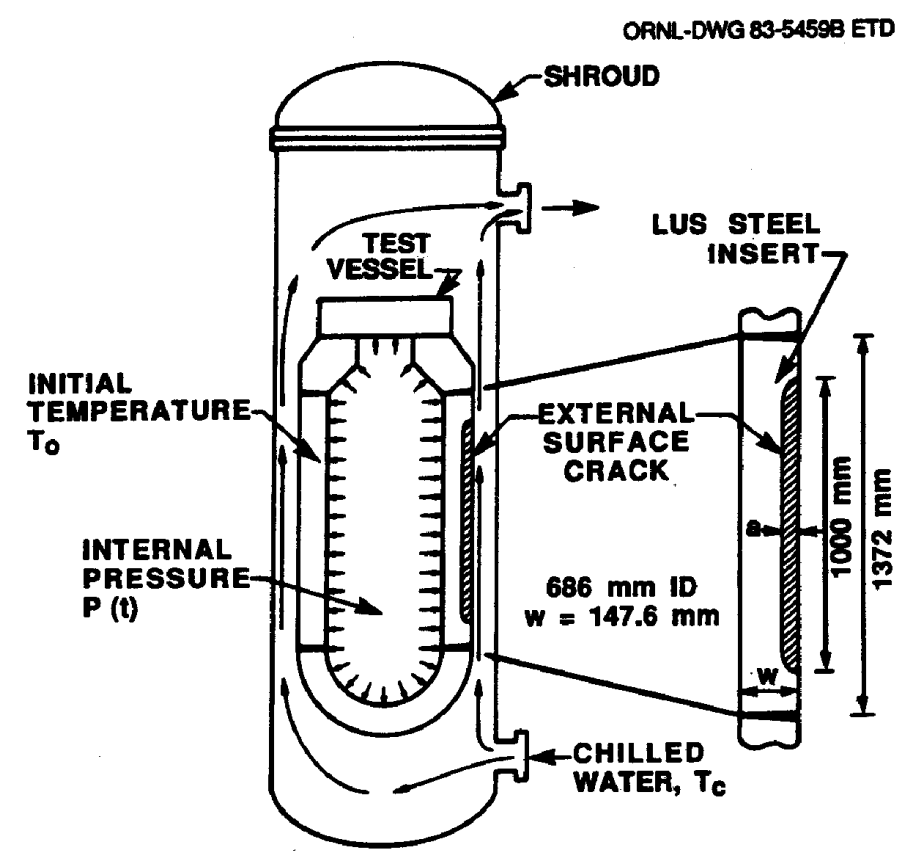

Fig. 7. Pressurized-thermal-shock (PTS) vessel inside shroud (ORNL, USA).

The first experiment, PTSE-1, was aimed at investigating (1) the effectiveness of warm prestressing (WPS) $[47,48]$, (2) rapid crack propagation into material at ductile upper-shelf temperatures, and (3) subsequent tearing stability in ductile regions. The test was composed of three transients, the first of which demonstrated that WPS was effective in inhibiting propagation of an otherwise critical crack. The second and third transients resulted in crack run/arrest events in which the crack extended axially and/or radially into the vessel wall. The cleavage initiation and arrest of a crack were well predicted by fracture analyses, and the arrest occurred at conditions that showed a toughness value greater than the limit suggested in the ASME BPV code. There were no coherent regions of ductile tearing following the two cleavage arrest events, contrary to predictions based on the measured tearing resistance of the material.

The second PTS experiment, PTSE-2, used a low-upper-shelf energy test material to simulate highly irradiated weld material. The primary objectives were to investigate (1) additional aspects of warm prestressing and (2) transitional crack behavior (i.e., from cleavage fracture to ductile tearing) in a steel with low tearing resistance under PTS loading conditions. The PTSE-2 test was carried out in two transients, the first of which produced stable ductile tearing before and after a brittle fracture. The second transient generated the conditions for deep brittle crack propagation, terminated by an arrest and conversion to ductile tearing under conditions conducive to a tearing instability. The experiment produced, with stress and toughness states representative of RPVs: (1) the arrest of a brittle fracture with an immediate tearing instability, and (2) brittle fracture following warm 
prestressing. In each phase, the fracture surface and test data suggest that crack arrest occurred prior to conversion from cleavage to ductile fracture. Another principal conclusion was that low-uppershelf material can exhibit very high cleavage arrest toughness.

\subsubsection{Sixth CRISM PTS experiment (PTS-I/6)}

The Central Research Institute of Structural Materials (CRISM "Prometey") performed experiments to investigate the behavior of surface flaws under PWR overcooling accident conditions. Seven experiments were performed with the same pressure vessel using five different flaw geometries. The specimen and test facility are depicted in Figs. 8 and 9, respectively. The vessel had a 150-mm wall thickness, and an axial finite-length $(350-\mathrm{mm})$ flaw was placed on the outside surface in the circumferential weld. The flaw extended into the base metal region of the vessel. The vessel was heated to $280^{\circ} \mathrm{C}$, internally pressurized, and subjected to a thermal shock by being subjected to a sudden flow of water $\left(15^{\circ} \mathrm{C}\right)$ around the outside. Cleavage fracture was initiated in the transition temperature range of the base metal. While the crack propagated into the base metal, there was very little propagation in the weld region, and there was essentially no axial extension of the flaw at the surface. However, there was tunneling of the flaw in the axial direction.

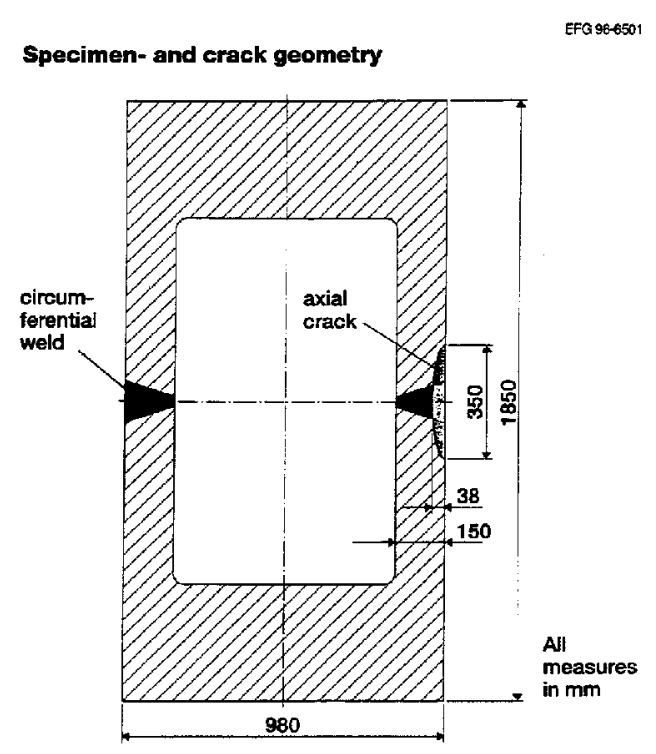

Fig. 8. Specimen and crack geometry used in PTS-I/6 experiment (Prometey Institute, Russia). 


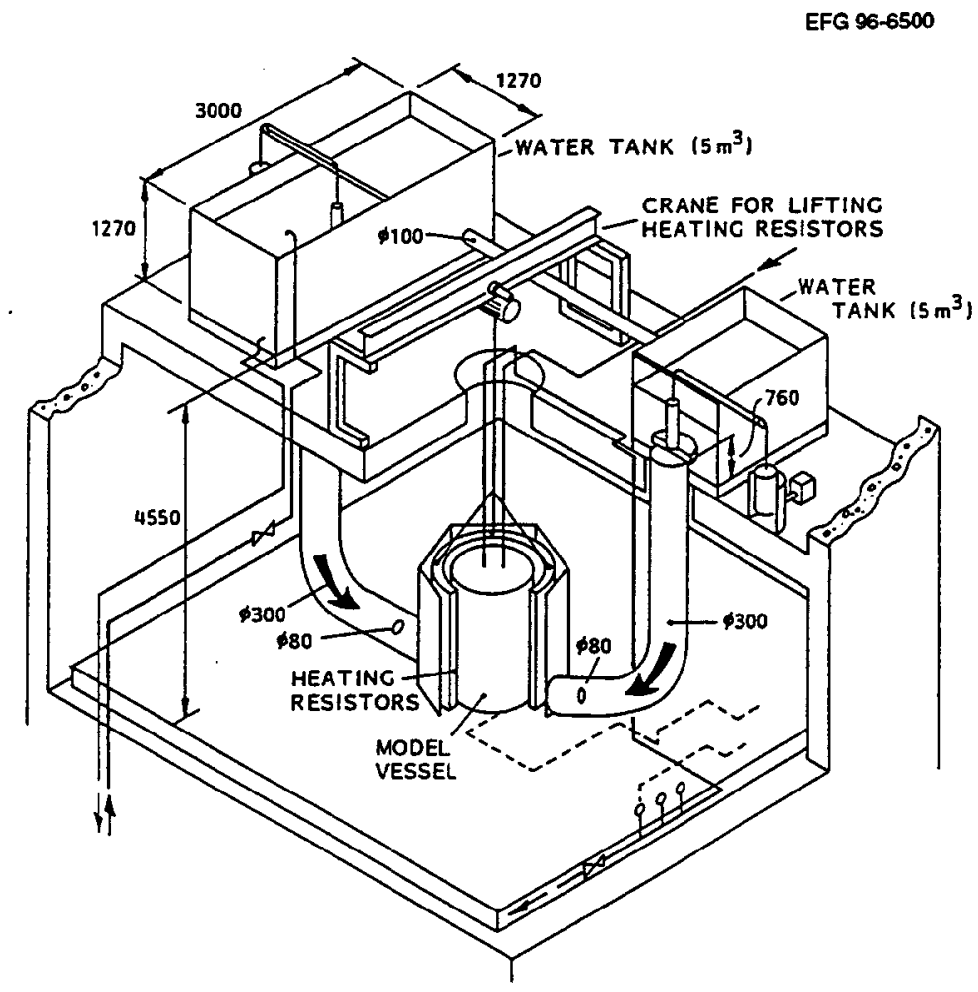

PTS-I/6 experiment (Prometey Institute, Russia).
Fig. 9. Test facility used to conduct the

\subsection{Tests with plate specimens}

\subsubsection{Wide-plate PTS Step B experiment}

References [32-34] describe the large plate PTS experiments performed by Japan Power Engineering and Inspection Corporation (JAPEIC). Figure 10 shows a schematic of the specimen that was used, and the Step B specimen was subjected to a tensile load (17.9 MN) and a bending (mechanical) load. The entire specimen was initially at a uniform temperature of $322^{\circ} \mathrm{C}$, and a thermal shock was applied by spraying one side of the plate with a coolant at a temperature of $91^{\circ} \mathrm{C}$. The specimen contained a finite-length semielliptical surface flaw oriented transverse to the longitudinal plate axis. The crack had a maximum depth of $23.1 \mathrm{~mm}$ and length of $118.4 \mathrm{~mm}$. The crack experienced stable ductile growth $(0.9 \mathrm{~mm}$ at the deepest point $)$ which was initiated at about 93 seconds into the transient.

Reference [34] provides the following assessment of Step B test results:

"In previous analyses, estimated stable crack growth at the deepest point of the crack was $2.5 \mathrm{~mm}$ and it was considerably larger than the experimental value. This big difference may be caused by finite-element mesh, triaxiality, and scatter of fracture toughness. In this paper, from the point of mesh refinement, reanalysis was carried out. In the new analysis, the minimum node length is 0.5 $\mathrm{mm}$ near the crack tip and is almost 22 percent of that of the previous mesh size. Material properties for the analysis are exactly the same as those of the previous analysis.

According to the new analysis, path independence is improved and estimated ductile crack growth becomes $2.0 \mathrm{~mm}$. That is, overestimation of the ductile crack growth reduces by adopting finer 
mesh near the crack tip. The difference between the experimental crack growth and the estimated value is in the same order as that in the NKS4-1 test analysis by MPA. To reduce overestimation still more, it is necessary to investigate the other two factors."

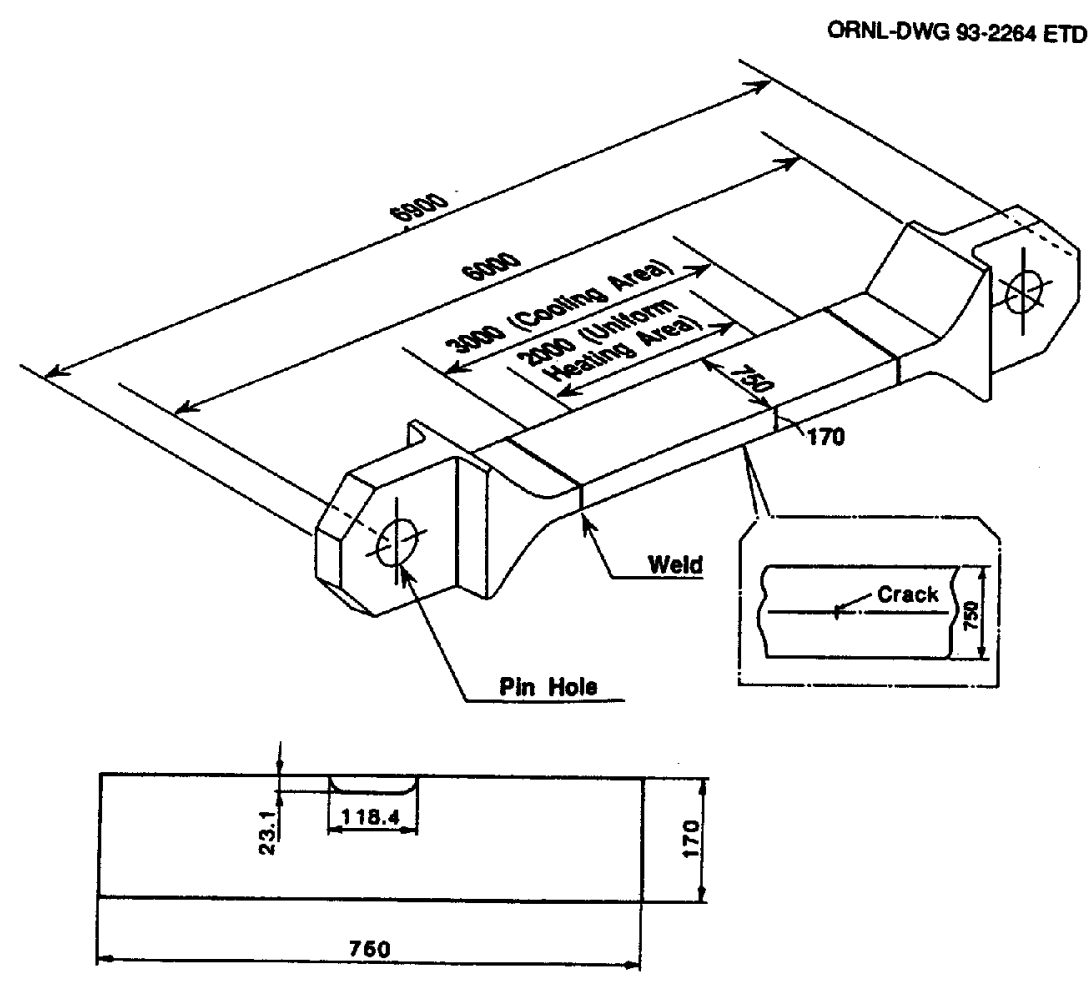

Fig. 10. Specimen and crack geometry for the Step B plate test (JAPEIC, Japan).

In summary, it still remains a challenge for the current fracture methodologies to accurately resolve differences between the calculated results and measured data. Whereas analysis refinement has been considered, the basic fracture models need further assessment to address the other contributing factors (multiaxiality and constraint).

\subsubsection{HSST wide-plate experiments}

Under the HSST program, ORNL conducted two series of wide-plate tests to investigate a number of issues: (1) the ability of a running crack to arrest in a rising K-field, (2) establish if cleavage propagation could continue into regions where the temperature exceeded the onset of Charpy upper-

shelf behavior, (3) establish if there is a limiting value of the $\mathrm{K}_{\mathrm{Ia}}$ similar to the $220 \mathrm{MPa} \sqrt{\mathrm{m}}$ included in the ASME Code, and (4) constraint effects associated with small thickness-to-ligament ratios. In these tests, the specimen, (shown schematically in Fig. 11) was subjected to a linear transverse temperature gradient such that the initial crack tip was below the material's $\mathrm{RT}_{\mathrm{NDT}}$, and the midpoint of the plate was near the temperature for onset of Charpy upper-shelf behavior. The specimen was loaded in tension until crack propagation occurred. The specimen pull-plate assembly was designed to be long enough to allow crack run/arrest events to occur before longitudinal stress waves could propagate to the ends of the pull plates and return to the crack plane. 
In the WP-1 Series of crack-arrest experiments, the test material was an RPV quality A533 Grade B steel that had an extensive property characterization database to support test interpretations. The observations made from these tests are summarized in [35-38]. Each specimen was carefully instrumented to measure temperature gradients, crack opening displacements, plastic-zone strains, and dynamic effects. Multiple cleavage crack-arrest and reinitiation events were observed for each test. In general, the results show that the materials can exhibit crack-arrest toughness values well above the maximum value of $220 \mathrm{MPa} \sqrt{\mathrm{m}}$ recognized in the ASME BPV Code, crack arrest can occur in a rising $\mathrm{K}$ field, and crack arrest occurred prior to cleavage propagation converting to ductile tearing. Also, cleavage propagation and crack arrest were observed to occur at temperatures in excess of the onset of upper-shelf behavior. Thus, very high crack-arrest values were obtained. Detailed discussions of ORNL analyses of these tests are given in [49].
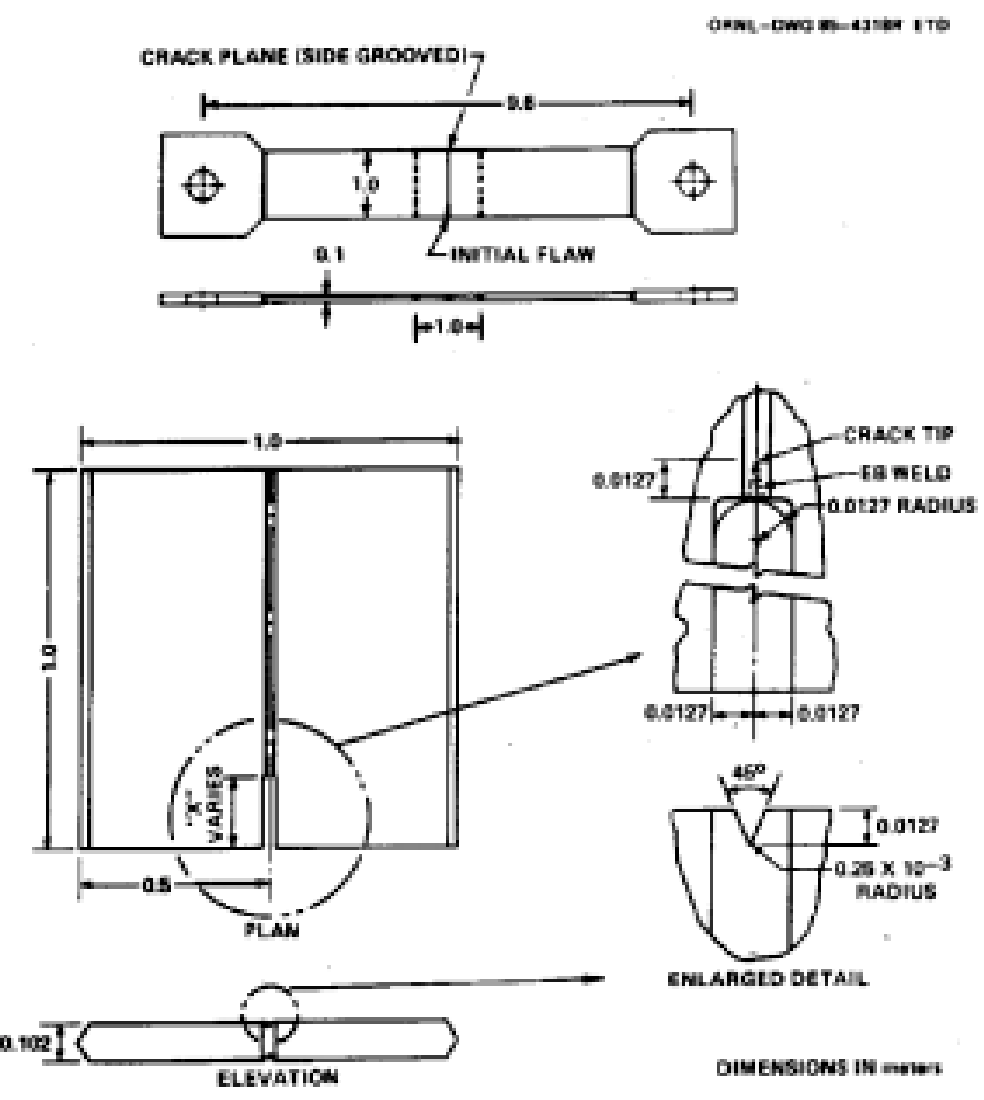

Fig. 11. HSST wide-plate, crack-arrest specimen (ORNL, USA).

Constraint effects were observed in the initiation of crack propagation in that the initiation loads were very high relative to predictions. Analyses performed by Dodds [50] demonstrated a significant loss of constraint in the wide-plate specimens caused by the inherent negative T-stress associated with this single-edge notch tension configuration. The high loads required to achieve cleavage initiation are attributed to this loss-of-constraint in the lower-transition temperature range of the material.

The second series of HSST Wide Plate Tests (WP-2) was designed to investigate the same phenomena in a low-upper-shelf material (heat-treated 2 1/4 Cr. 1-Mo steel). Figure 12 shows a 
specimen prior to being attached to the long pull plates for testing. The results for this material were characteristically the same as for the tougher material tested in the WP-1 Series. That is, multiple cleavage propagation-arrest-tearing-cleavage reinitiation events took place. Again final arrest locations were at temperatures well above those corresponding to the onset of Charpy upper-shelf behavior, and the corresponding crack-arrest toughness values were very high. Figure 13, from [35], shows a plot of these crack current toughness values along with those from other HSST tests: (WP-1 test series, TSE tests, and PTSE tests). (Note that the three points designated FTSE and those designated ESSO are not from HSST studies. Rather they are from studies conducted in France and Japan, see [51, 52], respectively.) These data are plotted against $\mathrm{T}-\mathrm{RT}_{\mathrm{NDT}}$ and formed a consistent trend that fall above the ASME KIR curve and extend to very high values.

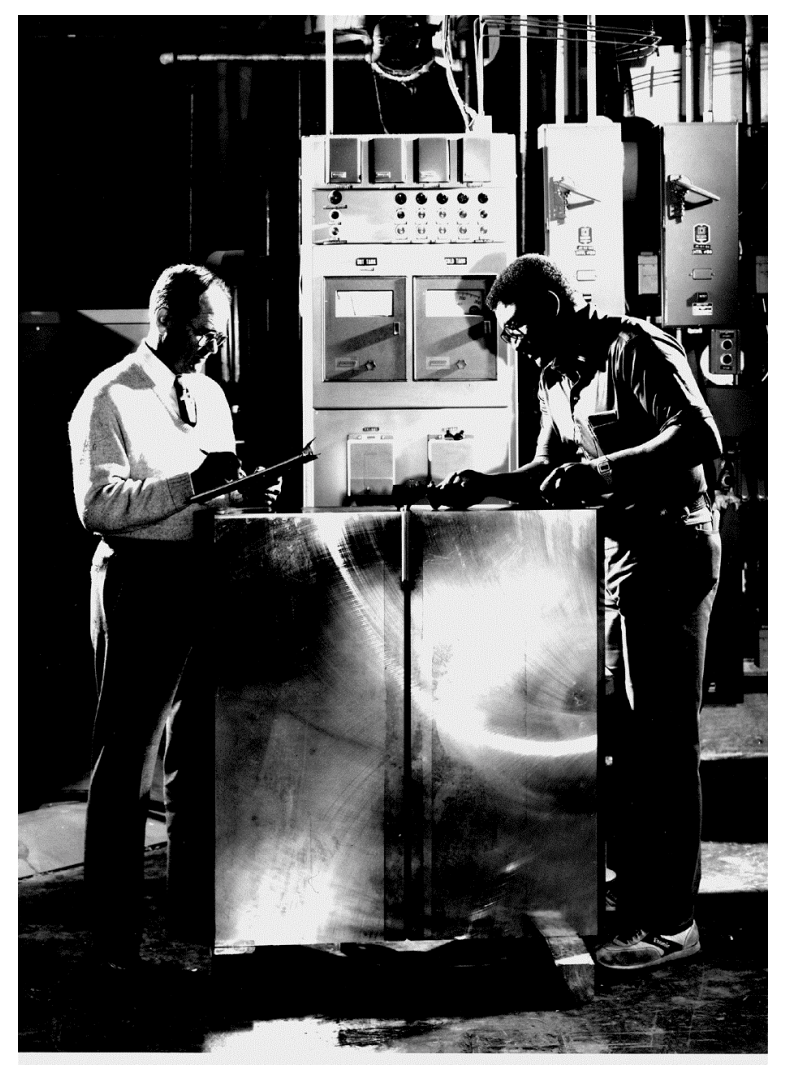

Fig. 12. HSST wide-plate specimen prior to being attached to long pull tabs (ORNL, USA). 


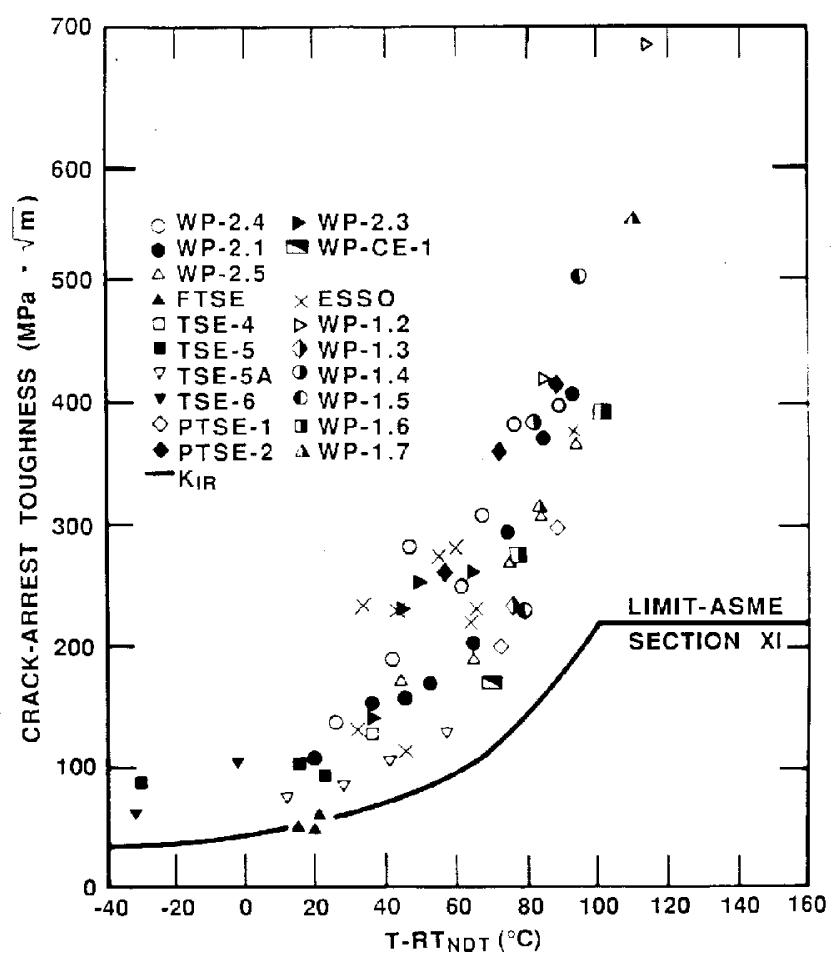

Fig. 13. High-temperature crack-arrest toughness data from large-specimen tests (ORNL, USA).

\subsubsection{MPA wide-plate experiments GP-1}

As a part of investigating the transferability of crack-arrest toughness values determined from small specimens to component-like large specimens, MPA-Stuttgart tested a series of wide-plate specimens. These tests are described in [39] and were carried out as part of the MPA program entitled, "Behavior of a Low-Toughness Pressure Vessel Steel at Fracture Initiation, Unstable Crack Propagation and Crack Arrest." The material used was a specially heat-treated MoV steel (designated as KS22) which had a low-upper-shelf Charpy energy (60J) and a high yield strength (1085 MPa at room temperature). The intent was for the properties of this material to be worse than the degraded properties (due to the effects of radiation) expected to be found in an RPV at the end of service. The specimen geometry is shown in Fig. 14, and the crack depth was $543 \mathrm{~mm}$ which gave an a/w value of 0.36 (same as for the ASTM E 399-81 specimen). A thermal gradient was imposed across the width of the specimen with the cold side at $195^{\circ} \mathrm{C}$ and the hot side at $337^{\circ} \mathrm{C}$. 


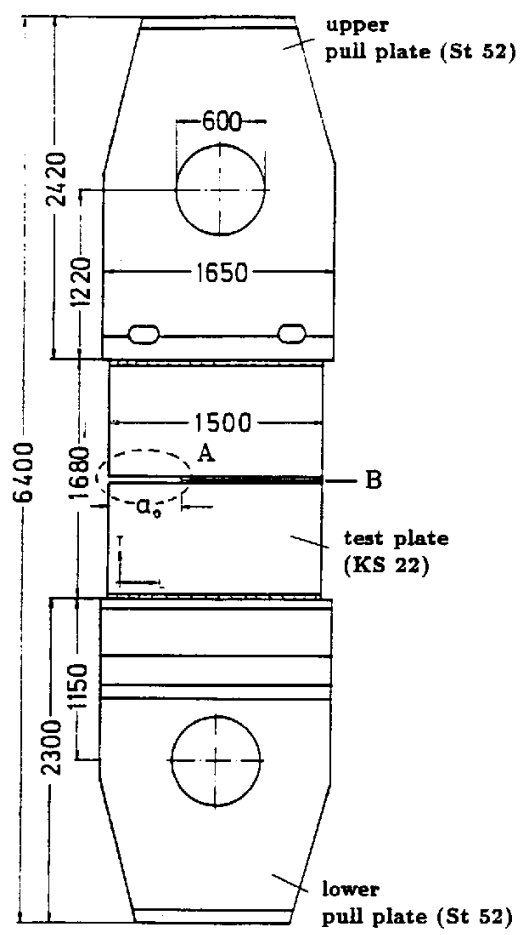

a.) front view, side $A$

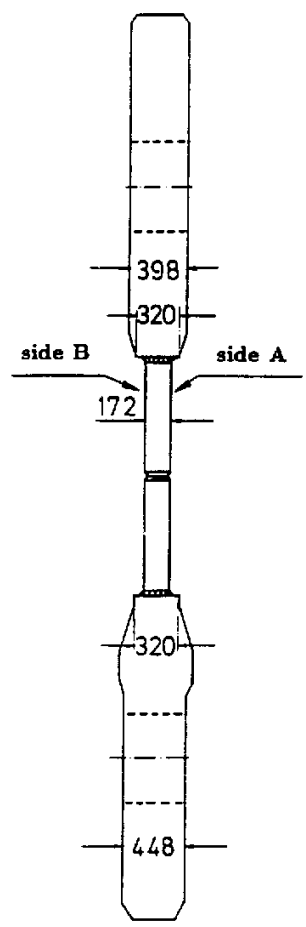

b.) side view

Fig. 14. Overall crack-arrest specimen GP-1 (dimensions in mm) (MPA, Germany).

The basic behavior observed from these experiments was similar to that observed in the two HSST WP test series discussed above. In particular, the GP-1 specimen showed multiple crack run/arrest events prior to unstable tearing. However, one significant difference from the WP-1 material is that the small-specimen crack-arrest data for the KS22 material indicated that $\mathrm{K}_{\mathrm{Ia}}$ values reach a maximum at a particular temperature and then decrease as the temperature increases further. This feature is very different from the results shown in Fig. 13, and the basis for this difference is still unresolved. The impact of this difference is lessened by the fact that reference curves in documents, such as the ASME BPV code, assume the existence of a limiting value of crack-arrest toughness [220 $\mathrm{MPa} \sqrt{\mathrm{m}}]$.

\subsection{Tests with beam specimens}

\subsubsection{Clad-beam experiments DD2 and DSR3}

A series of tests was performed by Electricité de France (EdF) to provide data for evaluating different methods of fracture analysis and to investigate the effects of cladding. Two of these experiments (DD2 and DRS3) were included in the FALSIRE Project [1,2]. Figures 15 and 16 illustrate the four-point bending loading system and specimen used in this series. The beams had underclad semielliptical cracks whose dimensions were $4.5 \times 48$ and $13 \times 40 \mathrm{~mm}$ for tests DD2 and DRS3, respectively. The tests were performed at low temperatures $\left(-165^{\circ} \mathrm{C}\right)$ to simulate radiationembrittled condition. The central part of the beams was made of A508 Class 3 steel, and the overall dimensions of the beams were $120 \times 145 \times 1780 \mathrm{~mm}$. The thickness of the type 309L stainless steel cladding was 6.0 and $4.5 \mathrm{~mm}$ for the specimens used in tests DD2 and DRS3, respectively. 


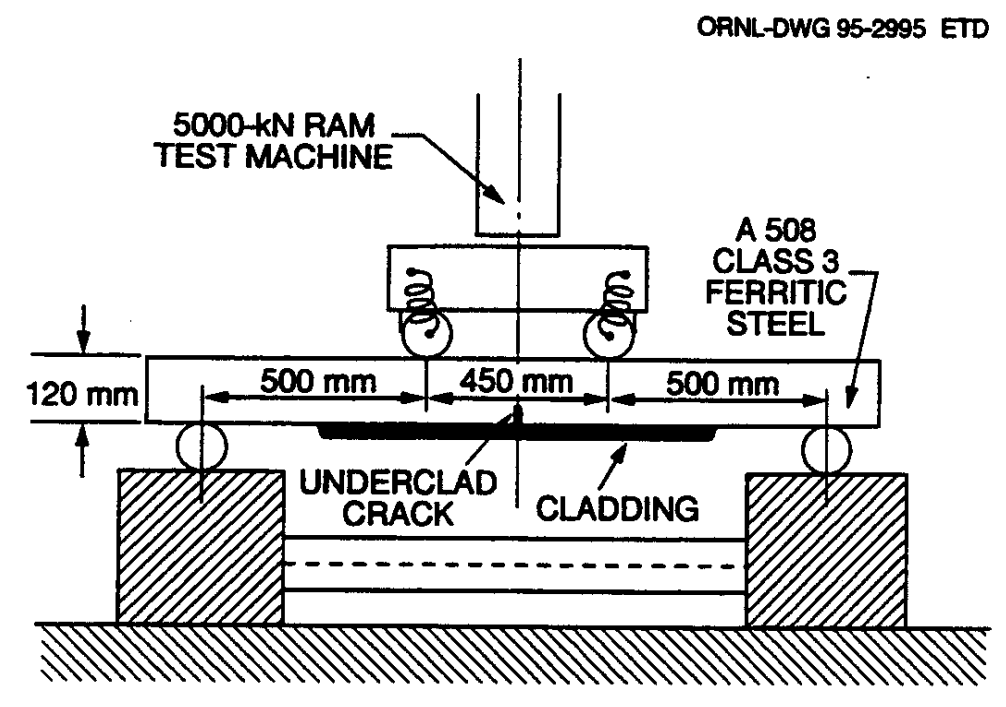

Fig. 15. Test frame used in four-point bending fracture experiments (EdF, France).

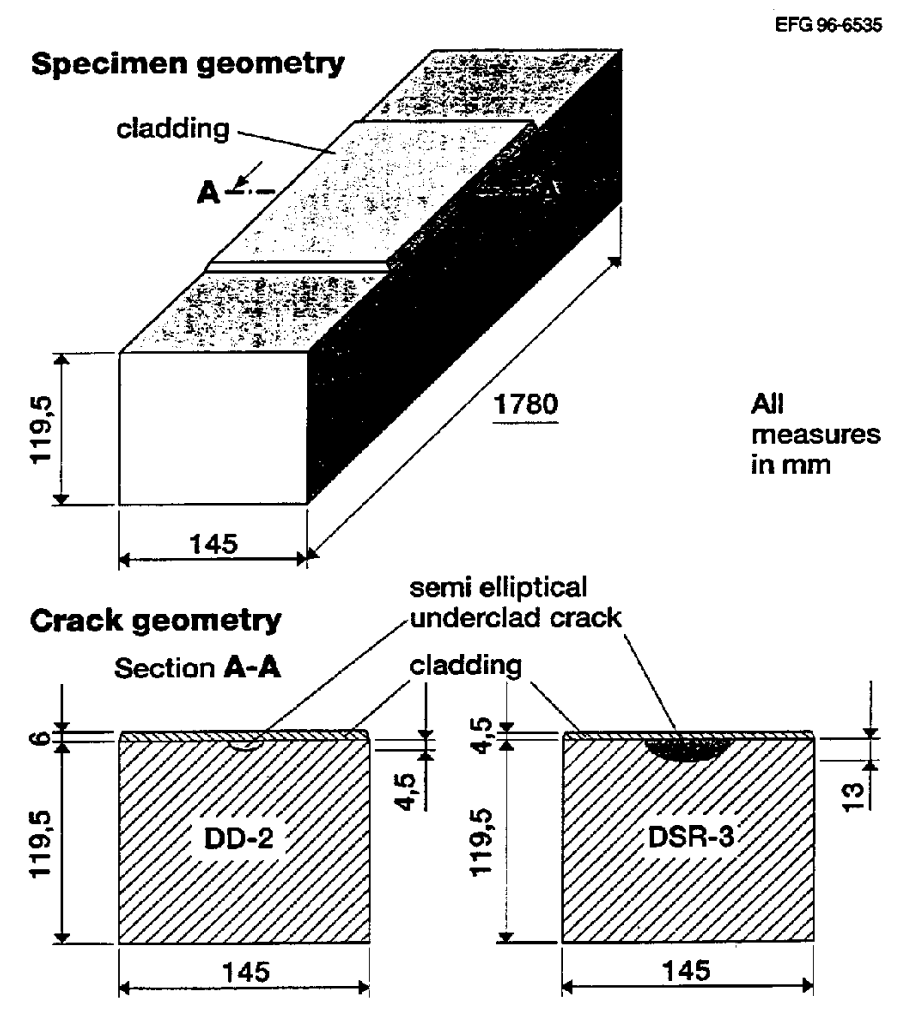

Fig. 16. Clad bend-bar specimens, DD2 and DSR3, containing shallow semielliptical underclad cracks (EdF, France).

The DD2 specimen fractured at a load of $890 \mathrm{kN}$ with no crack arrest. In DRS3, cleavage fracture initiated in the base material at $696 \mathrm{kN}$ with no crack arrest. In DD2, the highest computed values of $\mathrm{K}_{\mathrm{I}}$ at the fracture load were located at 30 degrees from the deepest point of the crack, and were 
between the lower- and upper-bound small-specimen fracture-toughness curves. However, crack propagation initiated in the heat-affected zone (HAZ) at 1.5 to $2.0 \mathrm{~mm}$ from the interface between the cladding and base metal. The computed toughness at the initiation site fell well below the lowerbound fracture toughness of the base metal at the test temperature. These results suggest lower fracture toughness for the HAZ than for the base metal. The results from the DSR3 test were similar to those from DD2 in that the propagation initiated in the HAZ about $2 \mathrm{~mm}$ from the interface. The computed toughness at the initiation site fell below the lower-bound fracture toughness of the base metal specimens at the test temperature. These results highlighted the need for improved models of cleavage fracture toughness in the HAZ. That need includes an improved understanding of (1) the role of locally intensified strain aging of materials that may occur near the tip of preexisting flaws when welding processes are performed, (2) irradiation effects on the HAZ, and (3) thermal aging effects on the HAZ.

\subsubsection{Full-thickness clad beam experiments}

Tests of full-thickness clad beams [single-edge notch bend (SENB) specimens] were conducted at ORNL to investigate and quantify effects of shallow-flaw geometry, metallurgical gradients, and residual stresses [41]. The SENB specimens are representative of RPV wall thickness and material properties in that they were fabricated from RPV shell segments taken from a pressurized-water reactor plant, which was canceled during construction. The RPV material was A533B steel with a stainless-steel strip-clad overlay on the inner surface. Eight beam specimens were cut from the shell segment shown in Fig. 17 (approximately 230-mm thick). A 2-D test flaw was machined into the inside clad surface, with the crack tip located in the shell segment structural material. Beams with normalized flaw depths (a/W ratios) of $0.05,0.1$, and 0.5 were tested. A test using a single deep-flaw

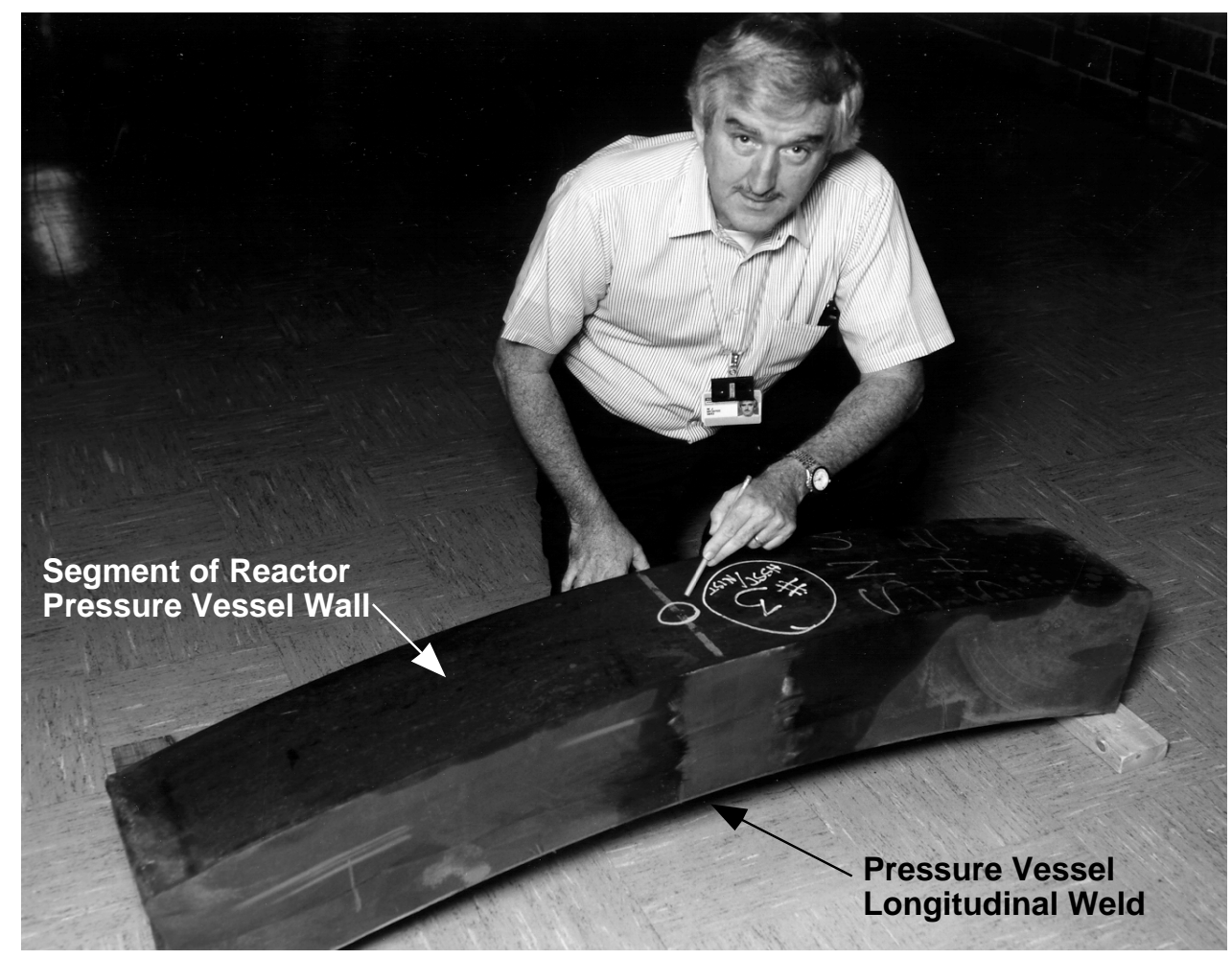

Fig. 17. Prototypical flaw depths and metallurgical gradients were used in full-thickness beam tests (ORNL, USA). 
beam provided the baseline for this series. The depths of the shallow flaws in the remaining beams were consistent with flaw depths of interest in PTS assessments. Five specimens had the flaw located in the longitudinal structural weld joining the shell plates, while the remaining three had the flaw in plate metal.

Results showed a large variation in fracture toughness (i.e., ranging from 225 to $437 \mathrm{MPa} \sqrt{\mathrm{m}}$ ) for tests conducted at $\mathrm{T}=-25^{\circ} \mathrm{C}\left(\mathrm{T}-\mathrm{NDT}=34^{\circ} \mathrm{C}\right)$ on specimens containing through-thickness shallow flaws (approximately 11-mm deep) located near the edge of the cladding HAZ in weld material. Analyses were carried out to adjust the measured toughness data for effects of residual stresses that remain following post-weld heat-treatment [53]. Four of the clad beam tests experienced substantial ductile tearing that eventually converted to cleavage fracture. Effects of this precleavage ductile tearing on estimates of fracture toughness were investigated using finite-element techniques based on a Gurson model for void growth [54] and an element-extinction model for simulating crack growth [55]. Both the mean value of fracture toughness and data scatter are greater for these shallow-flaw data than for available deep-flaw data. This result has important implications should shallow-flaw data be used in probabilistic evaluations of RPVs under PTS loading events.

\subsubsection{Cruciform beam experiments}

A cruciform test specimen was developed at ORNL [56] to investigate the effects of biaxial loading on the shallow-flaw fracture toughness of pressure vessel steels. This was a complementary study to the full-thickness SENB specimen test series described in the previous paragraph. Under PTS conditions, a typical biaxial stress field can have one of the principal stresses aligned parallel to the crack front of a shallow surface flaw. This out-of-plane component has the potential to increase constraint in the region of the crack-tip plastic zone, and thereby reduce the shallow-flaw fracturetoughness enhancement. The cruciform specimen, shown schematically in Fig. 18, was developed to introduce a far-field, out-of-plane biaxial stress component that provides an approximation of the biaxial stress field in an RPV.

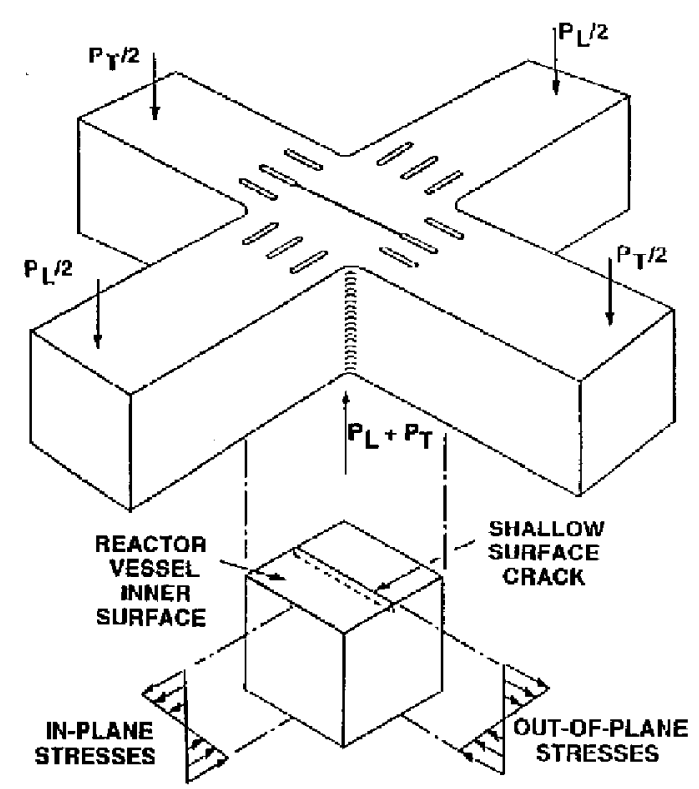

Fig. 18.

Cruciform beam specimen used in biaxial-loading effects tests (ORNL, USA). 


\subsubsection{Clad cruciform beam experiments}

The RPV shell-source material used for the full-thickness clad-beam specimens was also used to fabricate clad cruciform specimens with semielliptic surface flaws [57]. The specimens were machined from the inner half of the shell thickness, as shown schematically in Fig. 19. Loaddiffusion-control slots are machined into the specimen loading arms to create the boundary conditions required to achieve a uniform biaxial stress field in the central test section of the specimen. After EDM machining and fatigue precracking, the flaws had depth and surface length dimensions of $19 \mathrm{~mm}$ and $53 \mathrm{~mm}$, respectively. The test flaw was oriented with its major axis parallel to the direction of deposition of the structural weld. The leading edge of the test flaw passes through the clad material, the clad HAZ, and into the shell fabrication weld material. For each cruciform specimen, fatigue sharpening of the flaw was completed prior to attachment of the transverse loading arms by the electron-beam welding process. This design, coupled with a statically determinate load-reaction system, permits the specimen to be loaded in either uniaxial (four-point bending) or biaxial (eight-point bending) configurations.

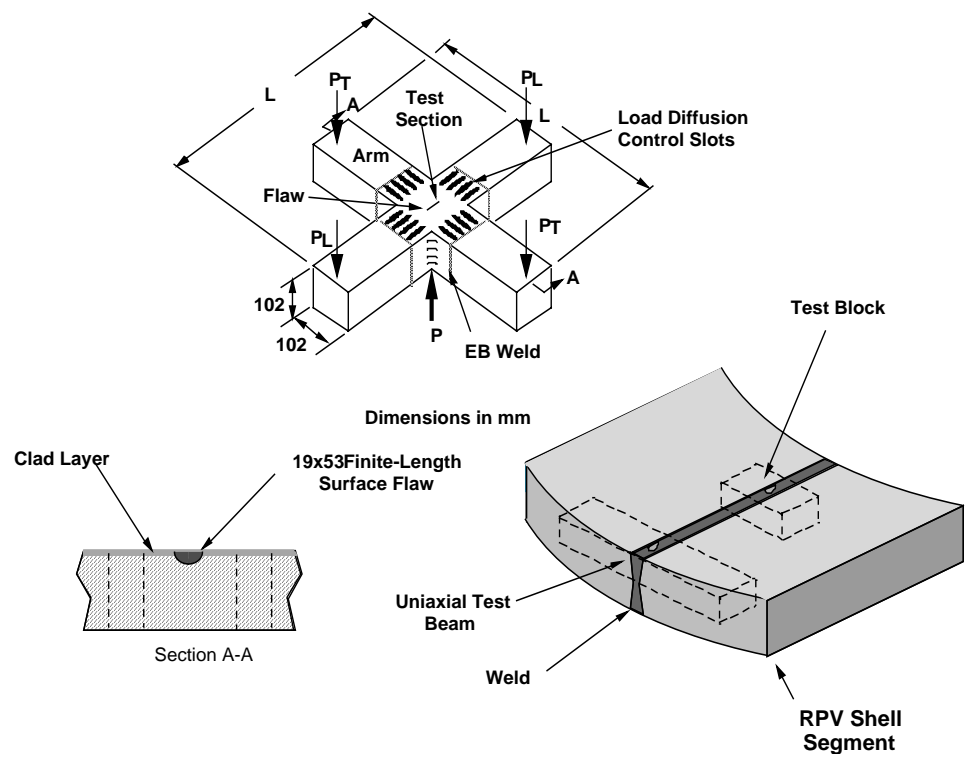

Fig. 19. Clad cruciform specimens cut from an RPV shell segment and used to investigate initiation behavior of prototypical RPV welds (ORNL, USA).

A total of 13 clad cruciform specimens were tested using biaxial load ratios, $P_{T} / P_{L}$, of $(0: 1)$ and $(1: 1)$. Fractographic data indicated that initiation-site location for the clad cruciform specimens was dependent upon biaxial load ratio and test temperature. Biaxial loading of the clad cruciform specimens tended to produce lower-fracture toughness, regardless of the initiation-site location. For the clad cruciform specimens tested under biaxial loading, the lowest toughness value is only slightly above the $\mathrm{K}_{\mathrm{Ic}}$ curve in Section XI of the ASME Code. 


\subsubsection{Base plate cruciform beam experiments}

ORNL also fabricated a series of cruciform specimens from A 533B steel (HSST Plate 14) which was heat treated to obtain an elevated yield strength. These specimens incorporated 2-D flaws and were tested with biaxial load ratios, $P_{T} / P_{L}$, of $(0: 1),(0.6: 1)$, and (1:1) and five temperatures through the transition-temperature region. The results demonstrated that biaxial loading can have a pronounced effect on shallow-flaw fracture toughness in the lower transition-temperature region. For temperatures near the Charpy lower-shelf region, essentially no biaxial effect was observed. At a temperature only $25^{\circ} \mathrm{C}$ higher, equibiaxial (1:1) loading reduced the toughness to approximately 58 percent of the average toughness obtained from uniaxial tests. Under conditions where a biaxial effect was observed, biaxial loading also affected the deformation at failure.

Results of these cruciform fracture-toughness tests were used to evaluate methodologies for predicting the observed effects of biaxial loading on shallow-flaw fracture toughness. Initial emphasis was placed on assessment of stress-based methodologies, namely, the $J-Q$ formulation [58], the Dodds-Anderson toughness scaling model [59], and the Weibull approach [60]. Applications of these methodologies based on the hydrostatic-stress fracture criterion indicated an effect of loadingbiaxiality on fracture toughness; the conventional maximum principal stress criterion indicated no effect. A detailed discussion of the development of these methodologies is given in Ref. [61]. 


\section{SUMMARY}

The previous portions of this report have discussed a number of large-scale experiments that have addressed issues and factors relevant to the behavior of RPVs under potential PTS scenarios. Some of these experiments have addressed the applicability of fundamental fracture behavior to thicksection structures, while others have addressed individual factors associated with PTS loadings (like those in Table 1), and yet others (e.g., the NESC-1 experiment) have integrated several features into a single experiment. Historically, the results have contributed significantly to confirmation of the applicability of fracture methodology and to development of codes and standards (such as Sections III and XI of the ASME BPV Code). The applicability of methodologies to cleavage fracture events has been relatively well demonstrated, including crack initiation, crack arrest, effectiveness of warm prestressing, etc. On the other hand, the behavior and challenges to modeling have been shown to be more complex at transition and upper-shelf temperatures. Based on results from the more recent tests, some areas receiving additional attention include: (1) effects of constraint, especially at temperatures in the transition region, (2) effects of multiaxial loading, and (3) modeling special features, such as cladding and HAZ regions. These efforts should continue to further develop an understanding of the margins that exist under PTS conditions.

Historically, large-scale testing and associated analytical efforts have served as a catalyst to international collaboration and the formation of multinational networks to assess and extend RPV technology. An even stronger emphasis on collaboration has developed over the past ten years, promoted by organizations both in western Europe and the United States. Within these collaborations, much attention has been given to PTS technology. In 1988 and 1992, the IAEA and NEA cosponsored two valuable specialists' meetings on large-scale experiments [3, 4]. Project FALSIRE was launched in 1989 and involved investigators from a large number of international research organizations who used several large-scale experiments to evaluate the conservatism in a variety of RPV safety assessment methodologies. FALSIRE was conducted under the OECD/Nuclear Energy Agency's sponsorship, with major support provided by governmental agencies within Germany and the U.S.

Beginning in 1991, the Joint Research Center of the European Commission (EC) initiated a series of international Networks for nuclear technology that would build upon successes of Project FALSIRE, as well as the Program for the Inspection of Steel Components (PISC) [62]. The first two Networks were launched in 1992: the European Network on Inspection Qualification (ENIQ), and the Aged Material Evaluation and Studies (AMES). The Network for Evaluation of Steel Components (NESC), co-sponsored by the U.K. Health and Safety Executive and the EC, was initiated in 1993 to study the entire process of RPV integrity assessment. The NESC projects engage a large number of leading international research organizations in evaluating all aspects of the structural integrity process (fracture methodologies, material properties determination, inspection capabilities, and experimental techniques) through well-controlled large-scale PTS-type experiments.

Two analytical projects were recently completed to evaluate integrity assessment methodologies applied to RPVs under PTS conditions. The first project is the International Comparative Assessment Study (ICAS) which involved a large number of international members who are comparing predictions of the behavior of a western RPV under realistic PTS scenarios. The second analytical project is the recently initiated IAEA WWER PTS Benchmark Exercise (WPB). The WPB evaluated the IAEA Guidelines on WWER PTS analysis in much the same manner that the ICAS project examined methods employed for the assessment of western reactor vessels under PTS conditions. It is expected that the emphasis on international collaborations will continue as technologies mature and as the budgets for individual research organizations decline. 
It is envisaged that the IAEA and NEA will also continue to play an important role in RPV technology transfer and coordination of such international collaborative efforts. For example, it is anticipated that another specialists' meeting on validation of fracture assessment methods through large-scale experiments will be held in the near future. Information from such meetings will join that from other specialists' meetings on irradiation effects, inspection technology, and component performance to further advance the overall technology applicable to analysis of potential PTS scenarios. It is anticipated that the networks will continue to promote international cooperative experiments in nuclear technology with strong leadership being provided by organizations within EC member states. 


\section{REFERENCES}

[1] Bass, B. R., Pugh, C. E., Keeney-Walker, J., Schulz, H., and Sievers, J., CSNI Project for Fracture Analyses of Large-Scale International Reference Experiments (Project FALSIRE), NUREG/CR-5997 (ORNL/TM-12307), Oak Ridge National Laboratory, December 1992.

[2] Bass, B. R., Pugh, C. E., Keeney, J., Schulz, H., and Sievers, J., CSNI Project for Fracture Analyses of Large-Scale International Reference Experiments (FALSIRE II), NUREG/CR-6460 (ORNL/TM-13207), Oak Ridge National Laboratory, April 1996.

[3] Kussmaul, K., Fracture Mechanics Verification by Large-Scale Testing, Proceedings of IAEA Specialists' Meeting, Staatliche Materialprufungsanstalt, Stuttgart FRG, May 25-27, 1988, Mechanical Engineering Publications Limited, London, 1991.

[4] Pugh, C. E., et al., Proceedings of the Joint IAEA/CSNI Specialists' Meeting on Fracture Mechanics Verification by Large-Scale Testing, October 26-29, 1992, NUREG/CP-0131 (ORNL/TM-12413), Oak Ridge National Laboratory, October 1993.

[5] Sievers, J., and Bass, B. R., "Comparative Assessment of Project FALSIRE - Results," Journal Nucl. Engr. Des., 152, pp. 19-38, 1994.

[6] Bass, B. R., et al., "CSNI Project for Fracture Analysis of Large-Scale International Reference Experiments (FALSIRE II), pp. 149-162, Proc. International Conference on Nuclear Engineering-4 (ICONE-4), Vol. 1, Part A, American Society of Mechanical Engineers, 1996.

[7] Sauter, A., "Recent Progress in PTS Research at MPA Stuttgart," French German Seminar, Technical Presentation 1.4, Electricite de France, Moret sur Loing, France, 1987.

[8] Stumpfrock, L., "FALSIRE Results for NKS-3 and NKS-4," pp. 151-188, IAEA/CSNI Specialists' Meeting on Fracture Mechanics Verification by Large-Scale Testing, Oak Ridge, Tennessee, October 26-29, 1992, USNRC Report NUREG/CP-0131 (ORNL/TM-12413), October 1993.

[9] Guth, W., Nguyen-Huy, T., Huber, H., and Weber, U., "The PTS Issue: Experiments and Numerical Analyses," pp. 321-337 Fracture Mechanics Verification by Large-Scale Testing, EGF/ES188, Ed. K. Kussmaul, Mechanical Engineering Publications, London, 1991.

[10] Stumpfrock, L., et al., "Fracture Mechanic Investigations on Cylindrical Large-Scale Specimens under Thermal-Shock Loading," Nucl. Engr. And Des., 144, pp. 31-44, 1993.

[11] Clayton, A. M., et al., "A Spinning Cylinder Tensile Test Facility for Pressure Vessel Steels," Paper G1/4, Proceedings of $8^{\text {th }}$ International Conference on Structural Mechanics in Reactor Technology, Brussels, Belgium, August 19-23, 1985.

[12] Lacey, D. J., and Leckenby, R. E., "Determination of Upper Shelf Fracture Resistance in the Spinning Cylinder Test Facility," pp. 1-6, 10th International Conference on Structural Mechanics in Reactor Technology, Vol. GF, 1989. 
[13] Morland, E., "Spinning Cylinder Experiments SC-I and SC-II: A review of Results and Analyses Provided to the FALSIRE Project," pp. 39-74, IAEA/CSNI Specialists' Meeting on Fracture Mechanics Verification by Large-Scale Testing, Oak Ridge, Tennessee, October 26-29, 1992, USNRC Report NUREG/CP-0131 (ORNL/TM-12413), October 1993.

[14] Lacey, D. J. et al., Spinning Cylinder Test 4: An Investigation of Transition Fracture Behavior for Surface Breaking Defects in Thick-Section Steel Specimens, AEA Technology Report AEA TRS 4098, June 1991.

[15] Sherry, A. H., Lidbury, D. P. G., and Clayton, A. M., "Influence of Scale and Biaxiality on the Fracture Behaviour of Containment and Pressure Vessel Steels," Paper S302-2, Proc. $3^{\text {rd }}$ JSME/ASME Joint International Conf. on Nucl. Engr. (ICONE-3), Kyoto, Japan, April 1995.

[16] Wintle, J. B., Hurst, R., and Hemsworth, B., "NESC-1 Project - Status Report After the Spinning of the NESC Cylinder," Proceedings of the 23rd MPA Seminar, October 1-2, 1997.

[17] Hurst, R. C., Hemsworth, B., and Wintle, J. B., "NESC: The Network for Evaluating Steel Components," pp. 163-171, Proc. International Conference on Nuclear Engineering-4, Vol. 1, Part A, American Society of Mechanical Engineers, 1996.

[18] Cheverton, R. D., Ball, D. G., Bolt, S. E., Iskander, S. K., and Nanstad, R. K., Pressure Vessel Fracture Studies Pertaining to the PWR Thermal Shock Issue: Experiments TSE-5, TSE-5A, and TSE-6, NUREG/CR-4249 (ORNL-6163), Oak Ridge National Laboratory, 1985.

[19] Cheverton, R. D., Ball, D. G., Bolt, S. E., Iskander, S. K., and Nanstad, R. K., Pressure Vessel Fracture Studies Pertaining to the PWR Thermal Shock Issue: Experiment TSE-7, NUREG/CR-4304 (ORNL-6177), Oak Ridge National Laboratory, 1985.

[20] Cheverton, R. D., "Large-Scale Thermal-Shock Experiments with Clad and Unclad Steel Cylinders," pp. 289-310, IAEA/CSNI Specialists' Meeting on Fracture Mechanics Verification by Large-Scale Testing, Oak Ridge, Tennessee, October 26-29, 1992, USNRC Report NUREG/CP-0131 (ORNL/TM-12413), October 1993.

[21] Cheverton, R. D., Iskander, S. K., and Ball, D. G., "Review of Pressurized-Water-ReactorRelated Thermal Shock Studies," pp. 752-766, Fracture Mechanics: Nineteenth Symposium (June 30 - July 2, 1986), American Society for Testing and Materials, ASTM STP-969, 1988.

[22] Cheverton, R. D., "Thermal Shock Experiments with Flawed Clad Cylinders," Nucl. Engr. and Des., 124, pp. 109-119, 1990.

[23] Derby, R. W., et al., "Test of 6-Inch-Thick Pressure Vessels Series 1: Intermediate Test Vessels V-1 and V-2," ORNL-4895, Oak Ridge National Laboratory, February 1974.

[24] Bryan, R. H., et al., "Test of 6-Inch-Thick Pressure Vessels Series2: Intermediate Test Vessels V-3, V-4, and V-6,” ORNL-5059, Oak Ridge National Laboratory, November 1975.

[25] Bryan, R. H., et al., "Test of 6-In.-Thick Pressure Vessels, Series 3: Intermediate Test Vessel $V$-7B,” NUREG/CR-0309 (ORNL/NUREG-38), Oak Ridge National Laboratory, October 1978.

[26] Merkle, J. G., et al., "Test of 6-In.-Thick Pressure Vessels, Series 4: Intermediate Test Vessels V-5 and V-9 With Nozzle Corner Cracks," ORNL/NUREG-7, Oak Ridge National Laboratory, August 1977. 
[27] Bryan, R. H., et al., "Test of 6-In.-Thick Pressure Vessels, Series 3: Intermediate Test Vessel V-8," NUREG/CR-0675 (ORNL/NUREG-58), Oak Ridge National Laboratory, December 1979.

[28] Bryan, R. H., et al., Pressurized-Thermal Shock Test of 6-in.-Thick Pressure Vessel, PTSE-1: Investigations of Warm Prestressing and Upper-Shelf Arrest, USNRC Report NUREG/CR-4106 (ORNL-6135), Oak Ridge National Laboratory, April 1985.

[29] Bryan, R. H., Merkle, J. G., Nanstad, R. K., and Robinson, G. C., "Pressurized Thermal Shock Experiments with Thick Vessels." pp. 767-783, Fracture Mechanics: Nineteenth Symposium (June 30 - July 2, 1986), American Society for Testing and Materials, ASTM STP-969, 1988.

[30] Bryan, R. H., et al., Pressurized-Thermal Shock Test of 6-in.-Thick Pressure Vessel, PTSE-2: Investigation of Low Tearing Resistance and Warm Prestressing, USNRC Report NUREG/CR-4888 (ORNL-6377), Oak Ridge National Laboratory, December 1987.

[31] Keinanen, H., et al., "Pressurized Thermal Shock Tests with Model Pressure Vessels Made of VVER-440 Reactor Steel," pp. 275-288, IAEA/CSNI Specialists' Meeting on Fracture Mechanics Verification by Large-Scale Testing, Oak Ridge, Tennessee, October 26-29, 1992, USNRC Report NUREG/CP-0131 (ORNL/TM-12413), October 1993.

[32] Okumura, H., et al., "PTS Integrity Study in Japan," pp. 395-400, 9th International Conference on Structural Mechanics in Reactor Technology, Vol. G, 1987.

[33] Okumura, H., et al., "PTS Integrity Study in Japan (Part 2)," pp. 7-12, 10th International Conference on Structural Mechanics in Reactor Technology, Vol. F, 1989.

[34] Yagawa, G., "EPFM Verification by a Large Scale Test," pp. 201-214, IAEA/CSNI Specialists' Meeting on Fracture Mechanics Verification by Large-Scale Testing, Oak Ridge, Tennessee, October 26-29, 1992, USNRC Report NUREG/CP-0131 (ORNL/TM-12413), October 1993.

[35] Pugh, C. E., Naus, D. J., Bass, B. R., and Keeney-Walker, J., "Crack Arrest Behavior of Reactor Pressure Vessel Steels at High-Temperatures," pp. 357-380, Fracture Mechanics Verification by Large-Scale Testing, Mechanical Engineering Publications Limited, London, 1991.

[36] Naus, D. J., et al., High-Temperature Crack-Arrest Behavior in 152-mm-Thick SEN Wide Plates of Quenched and Tempered A533 Grade B Class 1 Steel, Report NUREG/CR-5330 (ORNL11083), Oak Ridge National Laboratory, April 1989.

[37] Naus, D. J., et al., Crack-Arrest Behavior in SEN Wide Plates of Low-Upper-Shelf Base Metal Tested Under Nonisothermal Conditions: WP-2 Series, Report NUREG/CR-5451 (ORNL-6584), Oak Ridge National Laboratory, April 1989.

[38] Pugh, C. E., et al., "Wide-Plate Crack-Arrest Tests Utilizing a Prototypical Pressure Vessel Steel," International Journal of Pressure Vessels and Piping, 31, pp. 165-185, 1988. 
[39] Kussmaul, K., Gillot, R., and Elenz, T., "Full Thickness Crack Arrest Investigations on Compact Specimens and a Heavy Wide-Plate," pp. 551-572, IAEA/CSNI Specialists' Meeting on Fracture Mechanics Verification by Large-Scale Testing, Oak Ridge, Tennessee, October 26-29, 1992, USNRC Report NUREG/CP-0131 (ORNL/TM-12413), October 1993.

[40] Moinereau, D., et al., "Cleavage Fracture of Specimens Containing an Underclad Crack," ASME PVP-Vol. 233, Pressure Vessel Fracture, Fatigue and Life Management, American Society for Mechanical Engineers, 1992.

[41] Keeney, J. A., Bass, B. R., and McAfee, W. J., "Fracture Assessment of Weld Material from a Full-Thickness Clad RPV Shell Segment," Fatigue and Fracture Mechanics, 20th Volume, ASTM STP-1321, Eds: J. H. Underwood, B. D. McDonald, and M. R. Mitchell, American Society for Testing Materials, 1997.

[42] Bass, B. R., et al., "Evaluation of Constraint Methodologies Applied to a Shallow-Flaw Cruciform Bend Specimen Tested under Biaxial Loading Conditions," Fatigue, Fracture, and High Temperature Design Methods in Pressure Vessels and Piping - 1998, ASME PVP-Vol. 365, Proc. 1998 ASME Pressure Vessel and Piping Division Conference, San Diego, CA, July 1998.

[43] Lidbury, D. P. G., et al., "Prediction of the First Spinning Cylinder Test Using Continuum Damage Mechanics," Nuc. Engr. and Des., 152, pp. 1-10, 1994.

[44] Eripret, C., and Rousselier, G., "First Spinning Cylinder Test Analysis Using a Local Approach to Fracture," Nuc. Engr. and Des., 152, pp. 11-18, 1994.

[45] Merkle, J. G., Whitman, G. D., and Bryan, R. H., An Evaluation of the HSST Program Intermediate Pressure Vessel Tests in Terms of Light-Water-Reactor Pressure Vessel Safety, Report ORNL/TM-5090, Oak Ridge National Laboratory, November 1975.

[46] Whitman, G. D., Historical Summary of the Heavy-Section Steel Technology Program and Some Related Activities in Light-Water Reactor Pressure Vessel Safety Research, USNRC Report NUREG/CR-4489 (ORNL-6259), Oak Ridge National Laboratory, March 1986.

[47] Loss, F. J., Gray, R. A., and Hawthorne, J. H., "Significance of Warm Prestress to Crack Initiation During Thermal Shock," Nuc. Engr. and Des., 46, pp. 395-408, 1978.

[48] Loss, F. J., Gray, R. A., and Hawthorne, J. R., "Investigation of Warm Prestress for the Case of Small Delta T During a Reactor Loss-of-Coolant Accident," ASME Journal of Pressure Vessel Technology, 101, pp. 298-304, November 1979.

[49] Bass, B. R., et al., "Fracture Analyses of Heavy-Section Steel Technology Wide-Plate CrackArrest Experiments," pp. 691-723, Fracture Mechanics: Nineteenth Symposium (June 30 - July 2, 1986), American Society for Testing and Materials, ASTM STP-969, 1988.

[50] Dodds, R. H. JR., Constraint Effects on Fracture Initiation Loads in HSST Wide-Plate Test, Report NUREG/CR-6259 (ORNL/TM-12796), Oak Ridge National Laboratory, December 1994.

[51] Pellissier-Tanon, A., Sollogoub, P., and Houssin, B., "Crack Initiation and Arrest in an SA 508 Class-3 Cylinder under Liquid Nitrogen Thermal-Shock," Paper G/F 1/8, Vol. G/H, pp. 137-142, 7th International Conference on Structural Mechanics in Reactor Technology, Chicago, August 22-26, 1983. 
[52] Kanazawa, T., et al., "Study of Fast Fracture and Crack Arrest," SESA Journal of Experimental Mechanics, 21(2), pp. 78-88, February 1981.

[53] Keeney, J. A., Residual Stress Analysis of Full-Thickness Beam Specimens, Report ORNL/NRC/LTR-94/37, Oak Ridge National Laboratory, August 1995.

[54] Gurson, A. L., "Continuum Theory of Ductile Rupture by Void Nucleation and Growth: Part I Yield Criteria and Flow Rules for Porous Ductile Media," J. Engineering Materials and Technology, 99, pp. 2-15, 1977.

[55] Keeney, J. A., and Williams, P. T., "Fracture Analysis of Ductile Crack Growth in Weld Material from a Full-Thickness Clad RPV Shell Segment," Fatigue and Fracture Mechanics: 29th Volume, ASTM STP-1332, T. L. Panontin and S. D. Sheppard, Eds., American Society for Testing and Materials, 1998.

[56] McAfee, W. J., Bass, B. R., and Bryson, J. W., "Development of a Methodology for the Assessment of Shallow-Flaw Fracture in Nuclear Reactor Pressure Vessels," PVP-Vol. 346, pp. 8594, Proceedings of ASME Pressure Vessel and Piping Conference, Orlando, Florida, July 27-31, 1997.

[57] Bass, B. R., McAfee, W. J., Bryson, J. W., and Pennell, W. E., "Determination of Cladding Effects on Shallow-Flaw Fracture Toughness of Reactor Pressure Vessel Steel under Prototypic Biaxial Loading", Proc. 5th International Conference on Nuclear Engineering-5 (ICONE-5), Nice, France, May 26-30, 1997.

[58] O'Dowd, N. P., and Shih, C. F., "Family of Crack-Tip Fields Characterized by a Triaxiality Parameter: Part I - Structure of Fields," J. Mechanics and Physics of Solids, 39(8), pp. 989-1015, 1991.

[59] Dodds, R. H., JR., Anderson, T. L., and Kirk, M. T., "A Framework to Correlate a/W Ratio Effects on Elastic-Plastic Fracture Toughness $\left(\mathrm{J}_{\mathrm{c}}\right)$," International J. Fracture, 48, pp. 1-22, 1991.

[60] Ruggieri, C., and Dodds, R. H., JR., "Probabilistic Modeling of Brittle Fracture Including 3-D Effects on Constraint Loss and Ductile Tearing," Proceedings Int'l Conf. on Local Approach to Fracture (MECAMAT 96), Fontainebleau, France, 1996.

[61] Williams, P. T., Bass, B. R., and McAfee, W. J., "Application of the Weibull Methodology to a Shallow-Flaw Cruciform Bend Specimen Tested under Biaxial Loading Conditions," STP 1389, ASTM $31^{\text {st }}$ National Symposium on Fatigue and Fracture Mechanics, June 21-14, 1999, Cleveland, Ohio.

[62] Borloo, E., and Lemaitre, P., eds., "Non-Destructive Examination Practices and Results," Proceedings of the Joint CEC/OECD/IAEA Specialists' Meeting, Petten, Commission of European Communities Report, EUR 15906 EN, 8-10 March 1994. 


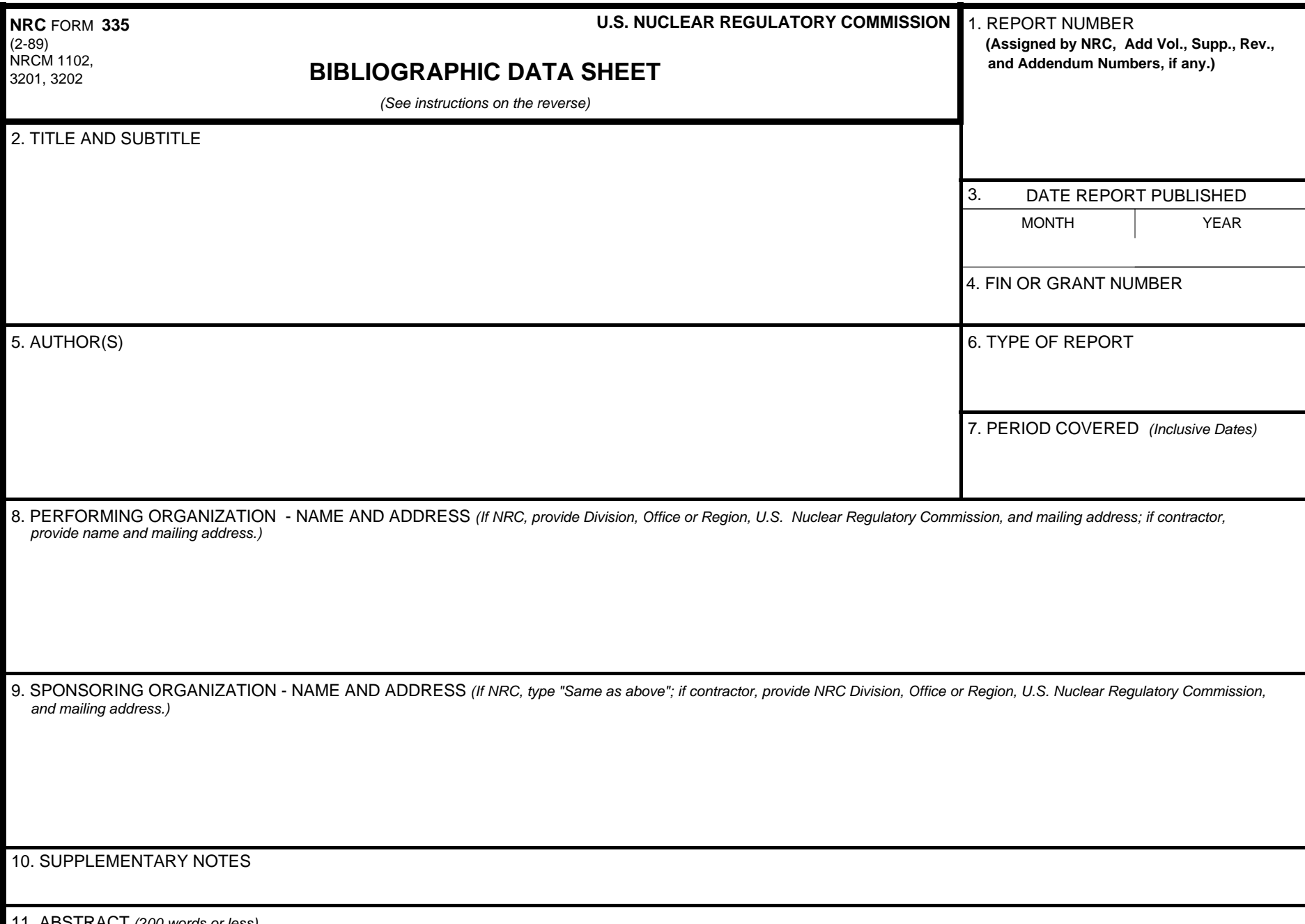

11. ABSTRACT (200 words or less)

Numerous large-scale fracture experiments have been performed over the past thirty years to advance fracture mechanics methodologies applicable to thick-wall pressure vessels. This report first identifies major factors important to nuclear reactor pressure vessel (RPV) integrity under pressurized thermal shock (PTS) conditions. This review covers twenty key experiments that have contributed to identifying fracture behavior of RPVs and to validating applicable assessment methodologies. The experiments are categorized according to four types of specimens: (1) cylindrical specimens, (2) pressurized vessels, (3) large plate specimens, and (4) thick beam specimens. These experiments were performed in laboratories in six different countries. This report serves as a summary of those experiments, and provides a guide to references for detailed information.

12. KEY WORDS/DESCRIPTORS (List words or phrases that will assist researchers in locating the report.)

Pressure vessels

Pressurized thermal shock

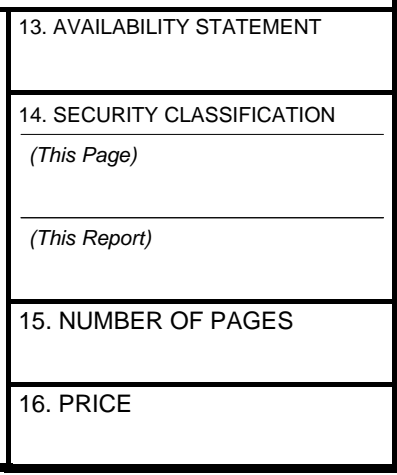

